(Aus dem staatl. serotherapent. Institut in Wien [Vorstand: Prof. Dr. R. Paltauf] und dem pathologisch-chemischen Laboratorium der k. k. Krankenanstalt Rudolfstiftung [Vorstand: Dr. E. Freund].)

\title{
Ueber \\ die Eiweissvertheilung in menschlichen und thierischen Körperflüssigkeiten ${ }^{1}$ ).
}

Von

Dr. Julius Joachim,

Assistent des path.-chem. Laboratoriums.

Die theils zu diagnostischen, theils zu prognostisehen Zwecken unternommenen Untersuchungen normaler und pathologischer Körperflüssigkeiten auf ihren Eiweissgehalt reichen bis in das fünfte Jahrzehnt des vergangenen Jahrhunderts, also in eine Zeit zurück, in der man dem Verhalten der "Säfte" ganz besondere Aufmerksamkeit geschenkt bat. Während sich die ersten Bearbeiter dieses Gebietes naturgemäss mit der quantitativen Bestimmung des Gesammteiweisses begnügen mussten, beschäftigte man sich seit etwa zwei Jahrzehnten der vorgeschrittenen Methodik entsprechend damit, aus dem Verhältniss vom Albumin zum Globulin, dem sogen. Eiweissquotienten, diagnostisch verwerthbare Gesichtspunkte zu gewinnen.

Die Trennung der beiden genannten Eiweisshauptgruppen wurde auf verschiedene Weise durchzuführen versucht:

1. Durch zehnfache Verdünnung der eiweisshaltigen Flüssigkeit, wodurch das früher durch Salze in Lösung gehaltene Globulin ausfällt, während das Albumin in Lösung bleibt.

Der gleiche Zweck wurde auch durch Dialyse der Flüssigkeit zu erreichen gesucht.

2. Durch Fällung der Globuline mittelst Essigsäure oder Kohlensäure.

1) Als kurze Mittheilung vorgetragen in der Sitzung vom 16. Mai 1902 der k. k. Gesellschaft der Aerzte in Wien (Wiener klinische Wochenschrift 1902 Nr. 21, Sitzungsbericht). 
3. Durch Aussalzen mit Neutralsalzen:

a) Nach Hammarsten(1) durch Sättigung der Flüssigkeit mittelst Magnesiumsulfat bei $30^{\circ} \mathrm{C}$. unter verschiedenen Cautelen, wobei das Globulin unlöslich wird, das Albumin in Lösung bleibt.

b) Durch die von Hofmeister angegebene, durch seine Schüler Pohl (2), Ka uder (3) u. A. ausgebaute Methode, welche darin besteht, dass in die eiweisshaltige Flüssigkeit so viel einer kaltgesättigten Lösung von schwefelsaurem Ammon eingetragen wird, bis die Mischung $46 \%$ an gesättigter Ammonsulfatlösung enthält. Bei dieser Grenze ist alles in der Flüssigkeit enthaltene Globulin ausgefallen, während die Ausscheidung des Serumalbumin erst beginnt, wenn durch weiteren Zusatz der Gehalt der Mischung an Ammonsulfatlösung $64 \%$ erreicht ist.

Während es bis vor wenigen Jahren als sicher galt, dass Serumglobulin in salzfreiem. Wasser unlöslich, Albumin darin löslich sei, - ein Satz, der nur von B u ck hard t (4) angezweifelt, von Hammarsten (5) streng verfochten wurde, gelang es Marcus (6), nachzuweisen, dass das bis dahin als einheitlich angesehene Globulin durch Dialyse in einen wasserlöslichen und in einen wasserunlöslichen Körper zerfällt.

Nachdem Spiro (7) durch Halbsättigung mittelst Kaliumacetat, E. P. Pick (8) durch fractionirte Fällung mittelst Ammonsulfat nach Hofmeister thatsächlich das Globulin in zwei Körper zerlegen konnten, nahm Spiro an, dass der eine mit dem wasserunlöslichen Globulin identisch sei, der andere sich mit dem wasserlöslichen decke, nannte den ersten Euglobulin, den zweiten Pseudoglobulin.

Wenn auch bisher aus dem Verhältniss von Globulin und Albumin zu einander gesetzmässige Beziehungen zu der Art der Erkrankung nicht gefunden werden konnten, war die Hoffnung doch nicht ganz unberechtigt, aus dem quantitativen Verhältniss der nunmehr neubekannten Globulinantheile einerseits zu einander, andererseits zum Albumin neue Aufschlüsse zu erwarten.

Dementsprechend ging ich daran, mittelst der fractionirten Fällung mit Ammonsulfat, die zwei bisher bekannten Globulinfractionen und das Albumin aus einer grösseren Reihe normaler und pathologischer Körperflüssigkeiten zu fällen, zu isoliren und quantitativ zu bestimmen.

Die gleichzeitig in Gemeinschaft mit E. Freund (9) indess durchgeführten Untersuchungen über die Natur des Eu- und Pseudo- 
globulins haben nun allerdings ergeben, $d a s s$ a $\mathrm{ch}$ diese beiden Globulinfractionen gleichfalls noch nicht einheitliche Körper darstellen, sondern aus mindestens je zwei Körpern zusammengesetzt sind, indem neben den wasserlöslichen Antheilen des Euglobulins und Pseudoglobulins noch wasserunlösliche vorhanden sind, die wir Para-Euglobulin und Parapseudoglobulin benannten ${ }^{1}$ ).

Da die Trennung der Globulinfractionen in ihre wasserlöslichen und wasserunlöslichen Theile bisher nur durch Dialyse, ein für quantitative Bestimmungen wenig geeignetes Verfahren, gelang, so sah ich vorläufig von dieser weiteren Zerlegung der beiden Fractionen ab. Die Bezeichnungen: Euglobulin und Pseudoglobulin beziehen sich in den nachfolgenden Untersuchungen also stets auf die Summe der wasserlöslichen und wasserunlöslichen Antheile der.entsprechenden Fractionea.

Hervorgehoben sei noch, dass ich auch auf eine Abtrennung des im Serum in nur sehr geringen Mengen vorkommenden Fibrinoglobulin keinen Werth gelegt, dasselbe vielmehr zugleich mit dem Euglobulin ausgefällt habe.

Zur Untersuchung gelangten Transsudate und Fxsudate, Menschenund Thierblutsera, eiweisshaltige Harne, je ein Ovarialeysten- und Hydrokeleninbalt und eine Oedemflüssigkeit.

\section{Methodik.}

\section{Transsudate und Exsudate.}

Dieselben wurden mir stets sofort nach der Entnahme mittelst Punction $^{2}$ ) zur Verfügung gestellt und von mir nach spontaner Abscheidung des Fibrins der Verarbeitung unterzogen: Es wurden ausschliesslich seröse Flüssigkeiten verwendet; Fälle, in denen Eiteroder Blutbeimischung nachzuweisen war, von der Untersuchung aus-

1) Eine Bestätigung dieser Befunde sehen wir in einer nach Drucklegung der vorliegenden Arbeit erschienenen Publication von O. Porges und K. Spiro, "Die Globuline des Blutserums". Hofmeister's Beiträge Bd. 3 S. 277, in welcher die Verfasser von der früher angenommenen Identität des wasserunlöslichen mit dem Euglobulin, sowie des wasserlöslichen mit dem $\mathbf{P}_{\text {seudoglobulin }}$ wieder abgehen.

2) In einem Falle von Peritonitis durch Probelaparatomie. 
Ueb. d. Eiweissvertheilung in menschl. und thier. Körperflüssigkeiten.

geschlossen. Ich bestimmte das specifische Gewicht, den Gesammtstickstoff, den Stickstoff der coagulablen Eiweisskörper, der Euglobulin-, der Pseudoglobulin- und der Albuminfraction. In einigen Fällen wurde die directe Bestimmung des Stickstoffs der coagulablen Eiweisskörper unterlassen; die bezüglichen Angaben in den folgenden Tabellen stellen dann die Summe aus den Stickstoffwerthen der drei Fractionen dar.

Der Stickstoff wurde nach dem Kjeldahl-Verfahren bestimmt, und aus den gewonnenen Zahlen der entsprechende Eiweissgehalt durch Multiplication derselben mit der von $\mathrm{König}$ und $\mathrm{K}$ isch (10) angegebenen Zahl 6,25 berechnet. Zur Bestimmung des Gesammtstickstoffes dienten in der Regel $25 \mathrm{ccm}$ der Flüssigkeit; die gleiche, mittelst Pipette genau gemessene Menge wurde bchufs Bestimmung des Stickstoffs der coagulablen Eiweisskörper in siedenden absoluten Alkohol eingegossen, zehn bis fünfzehn Minuten auf dem Wasserbad erhitzt, das Coagulum auf ein Filter gebracht, mit Wasser gewaschen, im Trockenschrank getrocknet und der Stickstoff bestimmung nach Kjeldahl unterzogen.

Mehrere Vergleichsbestimmungen, die ich mit directer Coagulation bei schwach essigsaurer Reaction anstellte, ergaben vollständige Uebereinstimmung mit den nach der eben geschilderten Methode gewonnenen Werthen.

Zur fractionirten Ausfällung der drei Eiweissfractionen verwendete ich jedes Mal je $50 \mathrm{ccm}$. Diese wurden mit dem halben Volum $(25 \mathrm{ccm})$ einer kaltgesättigten Lösung von Ammonsulfat vom specifischen Gewicht 1252 versetzt (Drittelsättigung mit Ammonsulfat), wodurch die Euglobulinfraction und das Fibrinoglobulin ausgefällt wird. Der entstandene Niederschlag ( $\mathrm{Ng}$. I.) wurde absetzen gelassen, auf ein Filter gebracht und so lange mit einer drittelgesättigten Ammonsulfatlösung $\left.{ }^{1}\right)$ gewaschen, bis das Waschwasser keine Coagulation mehr aufwies, also eiweissfrei war. Filtrat und Waschwasser wurden vereinigt und behufs Fällung des Pseudoglobulins durch Hinzufügung eines Drittels des Gesammtvolumens an gesättigter Ammonsulfatlösung auf Halbsättigung gebracht.

Der gebildete Niederschlag (Ng. II) wurde wieder auf ein Filter gebracht, mit balbgesättigter Ammonsulfatlösung ${ }^{2}$ ) so lange gewaschen, bis auch dieses Waschwasser sich als eiweissfrei erwies.

1) Ein Theil gesättigter Ammonsulfatlösung auf zwei Theile Wasser.

2) Ein Theil gesättigter Ammonsulfatlösung auf einen Theil Wasser. 
Zur Bestimmung der Albuminfractionen ging ich hierauf in zweifacher Weise vor: Einerseits trug jch in das mit dem Waschwasser vereinigte Filtrat des Niederschlags II bei $30^{\circ} \mathrm{C}$. so lange fein gepulvertes Ammonsulfat ein, bis die Lösung gesättigt war und brachte dann die hierdurch zur Fällung gelangte Albuminfraction (Ng. III) ebenfalls auf ein Filter. Andererseits unterzog ich bei der Doppelbestimmung das Filtrat und Waschwasser des Niederschlags II nach schwacher Ansäuerung mit Essigsäure im Wasserbade der Coagulation und habe dieses letztere weniger umständliche Verfabren, da es mit ersterem immer gut übereinstimmende Werthe lieferte, späterhin stets angewendet. Die direct durch Salzfällung gewonnenen Niederschläge (Ng. I, Ng. II und Ng. III) wurden mit dem Filter in Wasser gelöst, die Lösung nach mehrstündiger Einwirkung des Wassers von den Papierfasern filtrirt, das Filter his zum Schwinden der Ferro-Cyancalium-Essigsäure-Reaction gewaschen, die ganze Lösung im Wasserbade coagulirt. Hierauf wurden die Coagula auf Filter gebracht, im Trockenkasten getrocknet, mit heissem destillirten Wasser salzfrei gewaschen, bis weder durch Nessler's Reagens Ammoniak, noch durch Chlorbaryum und Salzsäure Schwefelsäure nachzuweisen war, dann mit absolutem Alkohol und Aether gewaschen, neuerdings getrocknet und sammt den Filtern dem KjeldahlVerfahren unterzogen.

Alle Bestimmungen wurden doppelt ausgeführt.

Das eben geschilderte Verfahren glaubte ich in allen Fällen gleichmässig beibehalten zu müssen. Bedenken, welche gegen dasselbe, insbesondere gegen eine scharfe quantitative Trennung der beiden Globulinfractionen in unverdünnten Eiweisslösungen geltend gemacht werden könnten, kamen bei meinen Untersuchungen nicht in Betracht, da es sich mir im Wesentlichen um relative Werthe handelte. Die in vielen Fällen zweckmässige Methode, in verdünnten Lösungen zu arbeiten, die Wallerstein (11) bei seinen gleichzeitig und unabbängig von mir durchgeführten Untersuchungen benützte, eignete sich für meine Fälle um so weniger, als durch eine willkürliche Verdünnung von Flüssigkeiten verschiedensten Eiweissgehaltes und verschiedenster Provenienz - und einen constanten Verdünnungscoëfficienten für eine bestimmte Eiweissconcentration konnte auch Wallerstein nicht feststellen ein unbestimmbarer Factor in die Berechnung eingeführt würde. Die Nothwendigkeit, in verdünnten Lösungen 
Ueb. d. Eiweissvertheilung in menschl. und thier. Körperflüssigkeiten. 563

zu arbeiten, lag um so weniger vor, als ich nicht, wie Wallerstein, mit $z$ wei verschiedenen Salzen (Kaliumacetat und Ammonsulfat) die Bestimmung der beiden Globulinfractionen herbeiführte, sondern dieselbe bei beiden Fractionen stets in einheitlicher W eise vornahm. Es leuchtet ohne Weiteres ein, dass bei der Vielheit der zur getrennten Bestimmung jeder Fraction nothwendigen Manipulationen geringe Verluste unvermeidlich sind, sei es bei der Fällung der einzelnen Fractionen, sei es bei dem Vorgang der Coagulation. Dadurch erklärt es sich, dass bei den nachfolgenden Bestimmungen vielfach Differenzen sich ergaben zwischen dem Stickstoff der coagulablen Eiweisskörper, wie er nach der Coagulation der gesammten Eiweisslösung ermittelt wurde, und zwischen dem aus der Summe der Stickstoffwerthe der für sich coagulirten Fractionen berechneten. Diese Differenzen betragen in der Regel nicht mehr als $1 \%$ bis $5 \%$, nur in wenigen Fällen sind sie erheblicher.

Die Thatsache, dass in keiner der früheren über ähnliche Untersuchungen veröffentlichten Arbeiten auf die durch die verwendete Methodik verursachten Eiweissverluste hingewiesen wird, spricht durchaus nicht für die grössere Exactheit der früheren Methodik, ist vielmehr dem Umstande zuzuschreiben, dass keiner der bisherigen Autoren die einzelnen Eiweissfractionen a $\mathrm{ch}$ wirklich getrennt bestimmte ${ }^{\mathbf{l}}$ ).

Die meisten begnügten sich mit der Bestimmung des Gesammteiweissgehaltes und des Globulins und gelangten durch Subtraction des für letzteren erhaltenen Werthes von ersterem zum Albuminwerth. W allerstein, der nur Bestimmungen der beiden Globulinfractionen vornahm und auf die des Albumins verzichtete, fällte das Gesammtglobulin durch Halbsättigung mittelst Ammonsulfat in einer Flüssigkeitsportion, das Euglobulin durch Halbsättigung mittelst Kaliumacetat $^{2}$ ) in einer anderen und erhielt durch Subtraction des Fuglobulins vom Gesammtglobulin den Werth für das Pseudoglobulin.

Durch den geschilderten Vorgang haben sich meiner Ansicht

1) Fine Ausnahme bildet $\mathrm{Paijkull,} \mathrm{dessen} \mathrm{später} \mathrm{citirte} \mathrm{Arbeit} \mathrm{mir} \mathrm{nur} \mathrm{im}$ Referat von Hammarsten zugänglich war.

2) O. Porges und K. Spiro heben in ihrer bereits citirten Arbeit hervor, dass das Euglobulin durch Halbsättigung mit Kaliumacetat nicht vollständig ausgesalzen werde, daher die Zahlen, wie man sie mit Kaliumacetataussalzung erhält, nicht mit den durch das Ammonsulfatverfahren gewonnenen, wohl aber untereinander vergleichbar seien. 
nach die bisherigen Bearbeiter des vorliegenden Themas der Selbstcontrole begeben.

Ich habe ausnahmslos Euglobulin, Pseudoglobulin und Albumin nacheinander aus ein und derselben Flüssigkeitsportion ausgefällt und bestimmt.

Ein Beweis für die möglichste Exactheit der von mir angewandten Methodik ist darin zu erblicken, dass die in allen Fällen gemachten Doppelbestimmungen stets gute Uebereinstimmung untereinander aufwiesen ${ }^{1}$ ). Fälle, bei denen die Doppelbestimmungen nicht bis in die dritte Decimalstelle übereinstimmten, wurden nicht verwerthet. Der Uebersichtlichkeit halber wird aber in den Tabellen nur der eine der gefundenen Werthe angegeben werden.

2. Von der Oedemflüssigkeit, dem Ovarialcysten- und dem Hydrokeleninhalt wurden je $50 \mathrm{ccm}$ verwendet. Erstere wurde in einem reinen Gefässe direct aus den Einstichöffnungen aufgefangen.

3. Die Verarbeitung der Thier-und Menschenblutsera geschah in der bei Transsudaten und Exsudaten üblichen Weise. Nach der Entnahme liess ich das Blut an einem kühlen Orte einige Zeit stehen, bis sich der Blutkuchen leicht ablösen liess; das Serum wurde abgegossen und bis zur völligen Klärung centrifugirt. Von den Thierblutseren wurden je $50 \mathrm{ccm}$ (in Doppelhestimmungen) der Fällung unterzogen, von den mittelst Venaesection gewonnenen Menschenblutseren standen mir zur fractionirten Eiweissfällung nur 10-20 cem, zur Bestimmung des Gesammtstickstoffs und des Stickstoffs der coagulablen Eiweisskörper je $4-5 \mathrm{ccm}$ zur Verfügung. Das untersuchte Placentarblutserum stammt aus dem retroplacentaren Blutkuchen einer gesunden Mutter, das Nabelschnurblutserum direct aus den Nabelgefässen ihres gesunden Kindes.

1) Gerade dieser Umstand lässt es nicht unwahrscheinlich erscheinen, dass die erwähnten Differenzen zwischen den direct durch Coagulation bestimmten und den durch Addition aus den drei Fractionen gewonnenen Gesammt-Eiweisswerthen nicht allein durch unvermeidlichen Arbeitsfehler zu er: klären sind, die ja kaum bei den Doppelbestimmungen stets in gleichmässiger Weise hätten gemacht werden müssen. Es ist vielmehr nicht ausgeschlossen, dass die direct bestimmten Eiweisswerthe dadurch etwas höher als der Wirklichkeit entsprechend ermittelt wurden, dass das coagulirende Eiweiss auch andere stickstoffhaltige Serumbestandtheile (z. B. nicht coagulirbare Eiweissstoffe, Extractivstickstoff u. s. w.) einzuschliessen und trotz Auswaschens festzuhalten im Stande ist. 
Ueb. d. Eiweissvertheilung in menschl. und thier. Körperflüssigkeiten. 565

4. In ganz analoger Weise gelangten die Harne von Nephritikern zur Untersuchung. Die sauer reagirenden Harne wurden der Vorschrift Pohl's entsprechend durch Ammoniak neutralisirt, filtrirt und dann erst mit dem halben Volum gesättigter Ammonsulfatlösung versetzt.

Einer Angabe Paton's (12) folgend, dass das Verhältniss vom Albumin zum Globulin im Verlaufe eines Tages mannigfach wechsle, wurden die Untersuchungen stets in den 24 stündigen Mengen von blut- und eiterfreien Harnen gemacht.

Alle Krankheitsfälle, denen ich mein Untersuchungsmaterial entnommen habe, unterlagen einer genauen klinischen Beobachtung; der Kürze wegen habe ich von der Veröffentlichung der Krankengeschichten Abstand genommen. Ein grosser Theil der Diagnosen wurde durch die in den Tabellen auszugsweise angeführten Obductionsdiagnosen bestätigt; in jenen Fällen, die nicht zur Autopsie gelangten, sind die Diagnosen gleichfalls sicher gestellt. Zweifelhafte Fälle wurden von der Veröffentlichung überhaupt ausgeschlossen. Die in den Tabellen angeführten Verhältnisszahlen der einzelnen Eiweissfractionen zu einander beziehen sich der Gleichmässigkeit halber stets auf die berechnete Summe aus ibrem Stickstoff- bezw. Eiweissgehalte, wobei dieselbe als 100 angenommen wurde.

In den Fällen, in welchen auch das Verhä]tniss des Stickstoffes der coagulablen Eiweisskörper zum Gesammtstickstoff angegeben erscheint, wurde der erstere stets in oben geschilderter Weise bestimmt. Wo diese Angabe fehlt, wurile der Stickstoff der coagulablen Eiweisskörper nur berechnet, nicht auch bestimmt. Die unter den Stickstoffwerthen in Klammern befindlichen Zahlen stellen die aus ersteren berechneten Eiweisswerthe dar.

\section{Transsudate und Exsudate.}

Die älteste Angabe über die Untersuchung einer Ascitesflüssigkeit auf ihren Eiweissgehalt dürte die von C. Schmidt (13) sein; ihm folgten Analysen von Hoppe $(14,15)$, Wachsmuth (16), Mehu (17) und Anderen. Diesen Untersuchungen eine klinisch verwerthbare Seite abzugewinnen, war der Zweck der Arbeiten von Reuss (18, 19) und Runeberg (20), welche eine empirisehe Formel gefunden haben wollten, mittelst welcher sie aus dem specifischen Gewichte den Eiweissgehalt der betreffenden Flüssigkeit berechneten und diesem wie jenem entscheidenden diagnostischen Werth beimaassen. 
Während Bernheim (21), Sansoni und Fornaca (22) u. A. sich diesem Verfahren anschlossen, kamen Neuenkirchen (23), Lunin (24) und insbesondere Citron (25) zu dem Schlusse, dass selbst die sorgfältigste Ermittlung des specifischen Gewichtes einen nur annähernden Schluss auf den Eiweissgehalt pathologischer Flüssigkeiten gestatte, und dass andererseits das specifische Gewicht wie der Eiweissgehalt nur mit grosser Vorsicht für die Diagnose zu verwenden, insbesondere bei niedrigen Werthen eine entzündliche Erkrankung nicht mit Sicherheit auszuschliessen sei. Die Wahrscheinlichkeit eines entzündlichen Processes wachse, je mehr das specifische Gewicht 1016, der Eiweissgehalt 3\% abberschreite. Eine Reihe von Untersuchungen des Eiweissgehaltes und des specifisehen Gewichtes in Ascites- und Oedemflüssigkeiten stammt von F. A. Hoffmann (26, 27, 28), v. Jaksch (29) und Ad. Ott (30); sie gelangen zu den gleichen Resultaten wie Citron.

F. A. Hoffm an $n$ dürfte auch der Erste gewesen sein, der auch Globulinbestimmungen angestellt hat; ihm folgten Fichtner (31), Mya und Viglezio (32), Csatàry (33) und Paijkull (34). Hoffmann, der das Globulin aus Ascitesflüssigkeiten mittelst Magnesiumsulfat fällte und den gefundenen Werth behufs Feststellung der Albuminzahl vom Werthe des Gesammteiweisses subtrahirte, gelangt zu folgenden Schlüssen: Der Eiweissquotient, i. e. das Verhältniss von Albumin zum Globulin, ist unabhängig vom Totaleiweissgehalt, schwankt in engen Grenzen und erlaubt keine Schlüsse auf die Natur der Erkrankung. Die quantitative Bestimmung des Albumins und Globulins in Ascitesflüssigkeiten hat nur theoretisches Interesse.

Im Gegensatz hierzu ziehen Mya und Viglezio, welche über die bisher grösste Untersuchungsreihe verfügen, und die bereits zur Trennung des Globulins vom Albumin sich des Ammonsulfats bedienten, in Bezug auf Aenderungen des Eiweissbestandes unter pathologischen Bedingungen weitgehende Folgerungen. Gleichzeitig mit Mya und Viglezio veröffentlichte Fichtner eine Untersuchungsreihe von 8 Ascitesflüssigkeiten, und Csatáry untersuchte einige ausschliesslich von Nephritikern stammende Ascitesund Oedemflüssigkeiten, sowie Blutsera in der Absicht, nachzuforschen, ob zwischen den Eiweisskörpern des Harnes, des Blutes und etwaiger Transsudate ein constantes Verhältniss bestehe mit negativem Resultat. Paijkull führten seine Untersuchungen über die von 
Ueb. d. Eiweissvertheilung in menschl. und thier. Körperflüssigkeiten. $\quad 567$

Hammarsten (35) in Ascitesflüssigkeiten gefundenen Mucoidsubstanzen zu Globulin- und Albuminbestimmungen in 15 Fällen von Transsudaten und Exsudaten, und schliesslich veröffentlicht Walle r stein in der bereits erwähnten Arbeit die Resultate der Untersuchung von drei pleuritischen Exsudaten schon unter Berücksichtigung der neueren Globulinforschung. Meine Untersuchungen erstreckten sich auf 42 Transsudate und Exsudate, und zwar: 10 Flüssigkeiten von acht an Carcinom der Bauchorgane erkrankten Patienten (zwei Patienten wurden je zwei Mal punktirt), 11 von vier an Cirrhosis hepatis leidenden (ein Patient wurde sechs Mal, zwei andere je zwei Mal punktirt), 4 von Hydrops Ascites bei Herzerkrankungen (ein Patient wurde zwei Mal punktirt), 4 von 4 an Peritonitis tuberculosa, 8 von 7 an Pleuritis exsudativa, 4 Hydrothoraxflüssigkeiten von drei an Herzaffectionen erkrankten Patienten und eine von einem Fall von Thrombosis Venae portae.

a) Punctionsflüssigkeiten der Pleurahöhle.

(Siehe Tabelle I und II S. 568 und 569.)

Bei der Pleuritis finden wir die Gesammtglobulinwerthe zwischen $40,85 \%$ und $50,31 \%$, die Albuminwerthe zwischen $49,68 \%$ und $59,14 \%$ des Gesammteiweis sgehaltes schwanken, beide demnach in der maximalen Amplitude von ca. 10\%. Grösseren Schwankungen sind die Euglobulinwerthe $(16,53 \%$ und $28,35 \%)$ und die Pseudoglobinwerthe $(19,92 \%$ und $31,41 \%)$ unterworfen.

Die Gesammtglobulinwerthe der Hydrothoraxfüssigkeiten schwanken nur zwischen $39,31 \%$ und $43 \%$, die Albuminwerthe zwischen $57 \%$ und $60,69 \%$ des Gesammteiweissgehaltes, die Euglobulinwerthe zwischen $10,99 \%$ und $15,09 \%$, die Pseudoglobulinwerthe zwischen $24,74 \%$ und $30,43 \%$. Wir sehen in den untersuchten Fällenvon Transsudaten der Pleurahöhle in allen drei Eiweissfractionen eine grössere Constanz als bei den Exsudaten.

Der Antheil, den das Euglobulin bei der Pleuritis vom Gesammtglobulin in Anspruch nimmt, bewegt sich zwischen 35,7\% und $56,3 \%$, beim Hydrothorax zwischen $27,2 \%$ und $37,9 \%$, ist als 0 gleichfalls bei letzterem viel constanter.

Nicht zu übersehen ist auch der Umstand, das die relativen Euglobulinwerthe beim Hydrotharax stets niedriger als bei der Pleuritis sind; der höchste Euglobulinwerth des 
Tabelle I. Pleuritis

\begin{tabular}{|c|c|c|c|c|c|}
\hline $\begin{array}{l}\text { Untersuchungs- } \\
\text { object. } \\
\text { Entnommen } \\
\text { am: }\end{array}$ & $\begin{array}{l}\text { Diagnose } \\
\text { (* Obductions- } \\
\text { diagnose) }\end{array}$ & $\begin{array}{l}\text { spec. } \\
\text { Ge- } \\
\text { wicht }\end{array}$ & $\begin{array}{l}\text { Gesammt- } \\
\text { Stickstoff }\end{array}$ & $\begin{array}{l}\text { Stickstoff } \\
\text { der coagu- } \\
\text { lablen } \\
\text { Eiweiss- } \\
\text { körper }\end{array}$ & $\begin{array}{l}\text { Stickstoff } \\
\quad \text { der } \\
\text { Euglo- } \\
\text { bulin- } \\
\text { fraction }\end{array}$ \\
\hline & & & \multicolumn{3}{|c|}{ auf $100 \mathrm{ccm}$ Flüssig- } \\
\hline $\begin{array}{l}\text { Punctionsflüssig- } \\
\text { keit aus dem } \\
\text { Thorax } \\
\text { 15. März } 1902 \\
\text { id }\end{array}$ & $\begin{array}{l}\text { I. Fall: } \\
\text { Pleuritis dextra; tu- } \\
\text { berculosis pulmon. } \\
\text { * 29. April } 1902 \\
\text { II. Fall. }\end{array}$ & 1022 & $0,816 \mathrm{~g}$ & $\begin{array}{c}0,7898 \mathrm{~g} \\
(4,9363 \mathrm{~g})\end{array}$ & $\begin{array}{c}0,1598 \mathrm{~g} \\
(0,9988 \mathrm{~g})\end{array}$ \\
\hline $\begin{array}{c}\text { 7. März } 1902 \\
\text { id. }\end{array}$ & $\begin{array}{c}\text { Pleuritis sinistra. . } \\
\text { IIr. Fall: }\end{array}$ & 1017 & $0,5635 \mathrm{~g}$ & $\left(\begin{array}{c}0,5145 \mathrm{~g} \\
(3,2156 \mathrm{~g})\end{array}\right.$ & $\left(\begin{array}{c}0,0935 \mathrm{~g} \\
(0,5844 \mathrm{~g})\end{array}\right.$ \\
\hline $\begin{array}{l}\text { 30. April } 1902 \\
\text { id. }\end{array}$ & $\begin{array}{c}\text { Pleuritis sinistra. } \\
\text { IV. Fall: }\end{array}$ & 1016 & $0,4515 \mathrm{~g}$ & $\left.\begin{array}{c}0,4396 \\
(2,7475 \\
\mathrm{g}\end{array}\right)$ & $\left.\begin{array}{c}0,0659 \\
(0,4119 \\
\mathrm{g}\end{array}\right)$ \\
\hline 10. Juni 1902 & $\begin{array}{c}\text { Pleuritis dextra Ne- } \\
\text { phritis chronica. } \\
\text { V. Fall: }\end{array}$ & 1017 & $0,637 \mathrm{~g}$ & $\begin{array}{c}0,5985 \mathrm{~g} \\
(3,7406 \mathrm{~g})\end{array}$ & $\begin{array}{c}0,1012 \mathrm{~g} \\
(0,6325 \mathrm{~g})\end{array}$ \\
\hline $\begin{array}{l}\text { 4. Juni } 1902 \\
\text { id. }\end{array}$ & $\begin{array}{c}\text { Pleuritis sinistra. . } \\
\text { VI. Fall: }\end{array}$ & 1020 & $0,8908 \mathrm{~g}$ & $\begin{array}{c}0,8435 \mathrm{~g} \\
(5,2719 \mathrm{~g})\end{array}$ & $\left(\begin{array}{cl}0,1652 & \mathbf{g} \\
(1,0325 & \mathrm{g})\end{array}\right.$ \\
\hline $\begin{array}{l}\text { 27. Juli } 1902 \\
\text { id. }\end{array}$ & $\begin{array}{c}\text { Pleuritis sinistra. . } \\
\text { VII. Fall: }\end{array}$ & 1022 & $0,903 \mathrm{~g}$ & $\begin{array}{c}0,8627 \mathrm{~g} \\
(5,392 \mathrm{~g})\end{array}$ & $\begin{array}{c}0,1708 \mathrm{~g} \\
(1,0675 \mathrm{~g})\end{array}$ \\
\hline 1. Juli 1902 & $\begin{array}{l}\text { Pleuritis dextra } \\
\text { 1. Punction . . }\end{array}$ & 1017 & $0,6554 \mathrm{~g}$ & $\begin{array}{cc}0,6169 & \mathrm{~g} \\
(3,8556 & \mathrm{g})\end{array}$ & $\begin{array}{c}0,1645 \mathrm{~g} \\
(1,0281 \mathrm{~g})\end{array}$ \\
\hline 30. August 1902 & 2. Punction. & 1019 & $0,6475 \mathrm{~g}$ & $\begin{array}{c}0,6985 \mathrm{~g} \\
(0,9594 \mathrm{~g})\end{array}$ & $\begin{array}{c}0,1512 \mathrm{~g} \\
(0,945 \mathrm{~g})\end{array}$ \\
\hline
\end{tabular}

Tabelle II.

Punctionsflüssigkeitaus der Brusthöhle

21. Februar 1902.

id.

7. Februar 1902

id.

24. Juli 1902

id.

23. August 1902
I. Fall ${ }^{1}$ : Myocarditis Hydrothorax Hydrops

Ascites ....

II. Fall:

Insufficientia valv. mitral. stenosis aortae ex Atheromatosi, Hydrothorax .

III. Fall:

Myocarditis Hypertrophia cordis $\mathrm{Hy}$ drothorax

1. Punction

id.

2. Punction ...

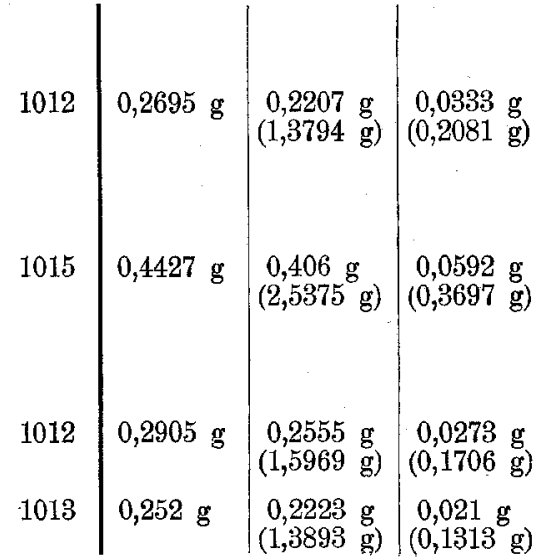

1) Siehe Tabelle IV Ascites bei cardialer Staung: I. Fall. 
Ueb. d. Eiweissvertheilung in menschl. und thier. Körperflüssigkeiten. 569 exsudativa serosa.

\begin{tabular}{|c|c|c|c|c|c|}
\hline $\begin{array}{l}\text { Stickstoff } \\
\text { der } \\
\text { Pseudo- } \\
\text { globulin- } \\
\text { fraction }\end{array}$ & $\begin{array}{c}\text { Stickstoff } \\
\text { der } \\
\text { Albumin } \\
\text { fraction }\end{array}$ & \multirow[t]{2}{*}{$\begin{array}{l}\text { Verhältniss } \\
\text { der drei } \\
\text { Eiweiss- } \\
\text { fractionen } \\
\text { zu einander } \\
\text { in } \%\end{array}$} & \multirow[t]{2}{*}{$\begin{array}{c}\text { Verhältniss } \\
\text { der Euglo- } \\
\text { bulin- } \\
\text { fraction zum } \\
\text { Gesammt- } \\
\text { globulin } \\
\text { in } \%\end{array}$} & \multirow[t]{2}{*}{$\begin{array}{c}\text { Verhältniss } \\
\text { des } \\
\text { Globulins } \\
\text { zum } \\
\text { Albumin } \\
\text { in } \%\end{array}$} & \multirow[t]{2}{*}{$\begin{array}{l}\text { Verhältniss } \\
\text { des Stickstoffs } \\
\text { der coagula- } \\
\text { blen Eiweiss- } \\
\text { körper zum } \\
\text { Gesammt- } \\
\text { Stickstoff } \\
\text { in } \%\end{array}$} \\
\hline \multicolumn{2}{|c|}{ keit berechnet } & & & & \\
\hline $\begin{array}{c}0,21 \mathrm{~g} \\
(1,3125 \mathrm{~g})\end{array}$ & $\begin{array}{c}0,42 \mathrm{~g} \\
(2,625 \mathrm{~g})\end{array}$ & $20,1: 27,09: 52,83$ & $42,6: 100$ & 47,19 & - \\
\hline $\begin{array}{r}0,1316 \mathrm{~g} \\
(0,8225 \mathrm{~g})\end{array}$ & $\left(\begin{array}{cc}0,2559 & \mathrm{~g} \\
(1,5994 & \mathrm{g})\end{array}\right)$ & $19,43: 27,36: 53,2$ & $41,5: 100$ & $46,79: 53,2$ & $91,3: 100$ \\
\hline $\begin{array}{c}0,1185 \mathrm{~g} \\
(0,7406 \mathrm{~g})\end{array}$ & $\begin{array}{c}0,2143 \mathrm{~g} \\
(1,3894 \mathrm{~g})\end{array}$ & $16,53: 29,72: 58,75$ & $35,7: 100$ & $46,25: 53,75$ & $97,3: 100$ \\
\hline $\begin{array}{l}0,1792 \mathrm{~g} \\
(1,12 \mathrm{~g})\end{array}$ & $\left(\begin{array}{cc}0,2902 & \mathrm{~g} \\
(1,8138 & \mathrm{g}\end{array}\right)$ & $17,73: 31,41: 50,86$ & $36: 100$ & $49,14: 50,86$ & $94: 100$ \\
\hline $\begin{array}{cc}0,1572 & \mathrm{~g} \\
(0,9825 & \mathrm{g})\end{array}$ & 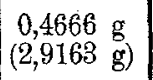 & $20,93: 19,92: 59,14$ & $51,2: 100$ & $40,85: 59,14$ & $94,6: 100$ \\
\hline $\begin{array}{c}0,1792 \mathrm{~g} \\
(1,12 \mathrm{~g})\end{array}$ & $\begin{array}{c}0,4536 \mathrm{~g} \\
(2,835 \mathrm{~g})\end{array}$ & $21,25: 22,3: 56,44$ & 48,$8 ; 100$ & $43,55: 56,44$ & $95,5: 100$ \\
\hline $\begin{array}{r}(0,1274 \mathrm{~g} \\
0,7963 \mathrm{~g})\end{array}$ & $\begin{array}{c}0,2882 \mathrm{~g} \\
(1,8012 \mathrm{~g})\end{array}$ & $28,35: 21,96: 49,68$ & $56,3: 100$ & $50,31: 49,68$ & $94,7: 100$ \\
\hline $\begin{array}{c}\left.0,133 \mathrm{gg}_{(0,8312} \mathrm{g}\right)\end{array}$ & $\left.\begin{array}{cc}0,3087 & \mathrm{~g} \\
(1,9294 & \mathrm{g}\end{array}\right)$ & $25,5: 22,43: 52,07$ & $53,2: 100$ & $47,93: 52,07$ & $97,8: 100$ \\
\hline
\end{tabular}

\section{Hydrothorax.}
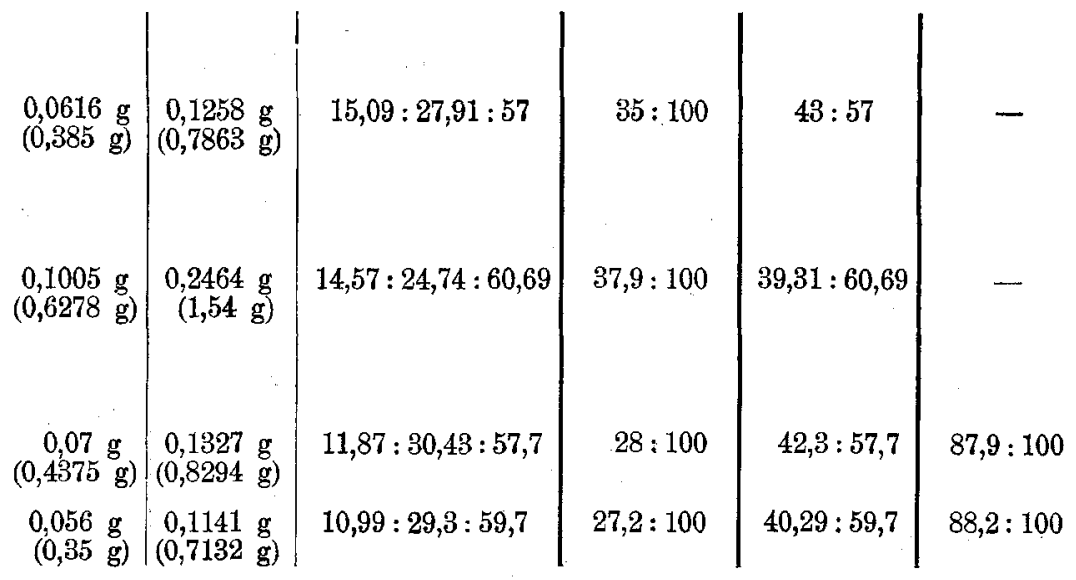
Tabelle III. Ascites

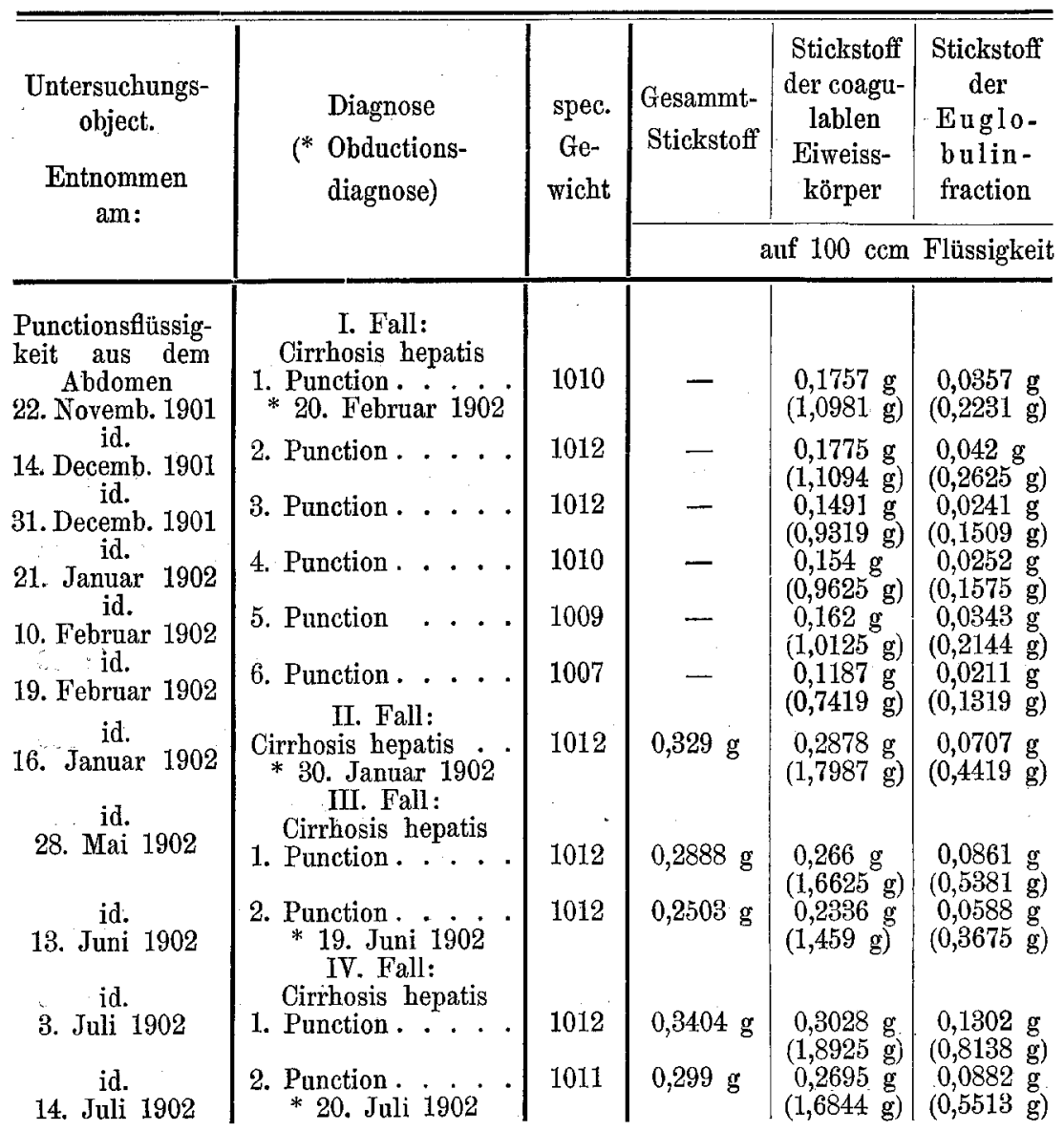

Tabelle IV. Ascites be i

Punctionsflüssigkeit aus dem $A b$ domen

30. Decemb. 1901

id.

15. Februar 1902

id.

19. Decemb. 1901

id.

7. August 1902
I. Fall: Myocarditis Hydrothorax, Hydrops Ascites

1. Punction. ...

2. Punction. .... II. Fall :

Myocarditis, Hydrops Ascites etc. . . . * 27. Juni 1902 III. Fall:

Hypertrophia cordis. Degeneratio parenchym. myocardii, $\mathrm{Hy}-$ dropericard, Hydrops Ascites . . . .

$\mid \begin{aligned} & 101 \\ & 10 \\ & 1\end{aligned}$

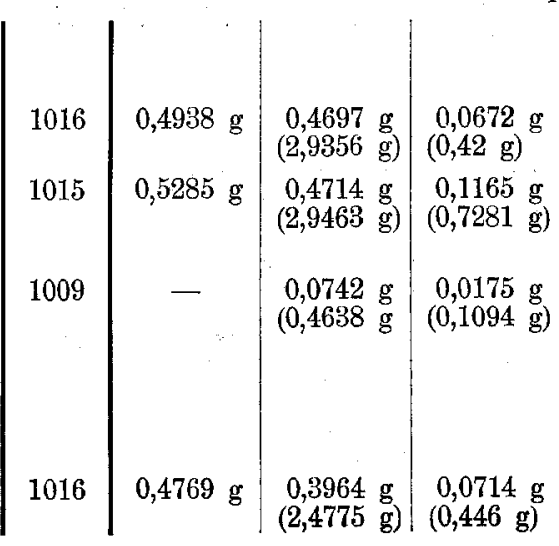


Ueb. d. Eiweissvertheilung in menschl, und thier. Körperflü ssigkeiten.

bei Cirrhosis hepatis.

\begin{tabular}{|c|c|c|c|c|c|}
\hline $\begin{array}{l}\text { Stickstoff } \\
\text { der } \\
\text { Pseudo- } \\
\text { globalin- } \\
\text { fraction }\end{array}$ & $\begin{array}{c}\text { Stickstoff } \\
\text { der } \\
\text { Albumin- } \\
\text { fraction }\end{array}$ & \multirow[t]{2}{*}{$\begin{array}{l}\text { Verhältniss der } \\
\text { drei Eiweiss- } \\
\text { fractionen } \\
\text { zu einander } \\
\text { in } \%\end{array}$} & \multirow[t]{2}{*}{$\begin{array}{l}\text { Verhältniss } \\
\text { der Euglo- } \\
\text { bulin- } \\
\text { fraction zum } \\
\text { Gesammt- } \\
\text { globulin } \\
\text { in } \%\end{array}$} & \multirow[t]{2}{*}{$\begin{array}{c}\text { Verhältniss } \\
\text { des } \\
\text { Globulins } \\
\text { zum } \\
\text { Albumin } \\
\text { in } \%\end{array}$} & \multirow[t]{2}{*}{$\begin{array}{l}\text { Verhältniss } \\
\text { des Stickstoffs } \\
\text { der coagula- } \\
\text { blen Eiweiss- } \\
\text { körper zum } \\
\text { Gesammt- } \\
\text { Stickstoff } \\
\text { in } \%\end{array}$} \\
\hline berechnet & & & & & \\
\hline $\begin{array}{l}0,05495 \mathrm{~g} \\
(0,3434 \mathrm{~g})\end{array}$ & $\left(\begin{array}{l}0,08505 \mathrm{~g} \\
(0,5316 \mathrm{~g}\end{array}\right)$ & $20,32: 31,27: 48,41$ & $39,3: 100$ & $51,59: 48,41$ & - \\
\hline $\begin{array}{rl}0,0571 & \mathrm{~g} \\
(0,3569 & \mathrm{g})\end{array}$ & $\begin{array}{c}0,0784 \mathrm{~g} \\
(0,49 \mathrm{~g})\end{array}$ & $23,66: 32,14: 44,17$ & $42,4: 100$ & $55,8: 44,17$ & - \\
\hline & & $16,19: 39,43: 44,36$ & $29,1: 100$ & $55,63: 44,36$ & - \\
\hline & & $16,36: 56,82: 26,82$ & $28,8: 100$ & $73,18: 26,82$ & - \\
\hline & & $21,17: 34,13: 44,7$ & $38,3: 100$ & $55,3: 44,7$ & - \\
\hline $\begin{array}{c}0,0419 \mathrm{~g} \\
(0,2619 \mathrm{~g})\end{array}$ & $\left(\begin{array}{cc}0,0557 & \mathrm{~g}) \\
(0,3481 & \mathrm{g})\end{array}\right)$ & $17,82: 35,26: 46,88$ & $33,5: 100$ & $53,08: 46,88$ & - \\
\hline $\begin{array}{c}0,1281 \mathrm{~g} \\
(0,8006 \mathrm{~g})\end{array}$ & $\left|\begin{array}{c}0,089 \mathrm{~g} \\
\left(0,5562^{\mathrm{g}}\right)\end{array}\right|$ & $24,56: 44,51: 30,92$ & $35,5: 100$ & $69,07: 30,92$ & - \\
\hline $\begin{array}{r}0,0883 \mathrm{~g} \\
(0,5519 \mathrm{~g})\end{array}$ & $\begin{array}{c}0,0903 \mathrm{~g} \\
(0,5644 \mathrm{~g})\end{array}$ & $32,52: 33,36: 34,11$ & $49,3: 100$ & $65,88: 34,12$ & $92,1: 100$ \\
\hline $\begin{array}{c}0,0826 \mathrm{~g} \\
(0,5163 \mathrm{~g})\end{array}$ & $\left(\begin{array}{c}0,0686 \mathrm{~g} \\
(0,4288 \mathrm{~g})\end{array}\right.$ & $28: 39,33: 32,67$ & $41,5: 100$ & $67,33: 32,67$ & $93,3: 100$ \\
\hline $\begin{array}{l}0,0945 \mathrm{~g} \\
(0,5906 \mathrm{~g})\end{array}$ & $\begin{array}{c}0,068 \mathrm{~g} \\
(0,393 \mathrm{~g})\end{array}$ & $45,26: 32,84: 21,89$ & $57,9: 100$ & $78,1: 21,89$ & $88,9: 100$ \\
\hline $\begin{array}{c}0,0777 \mathrm{~g} \\
(0,4856 \mathrm{~g})\end{array}$ & $\left.\begin{array}{c}0,084 \\
(0,525 \\
\mathrm{g}\end{array}\right)$ & $35,29: 31,09: 33,61$ & $53,1: 100$ & $66,38: 33,61$ & $90,1: 100$ \\
\hline
\end{tabular}

\section{cardialer staung.}

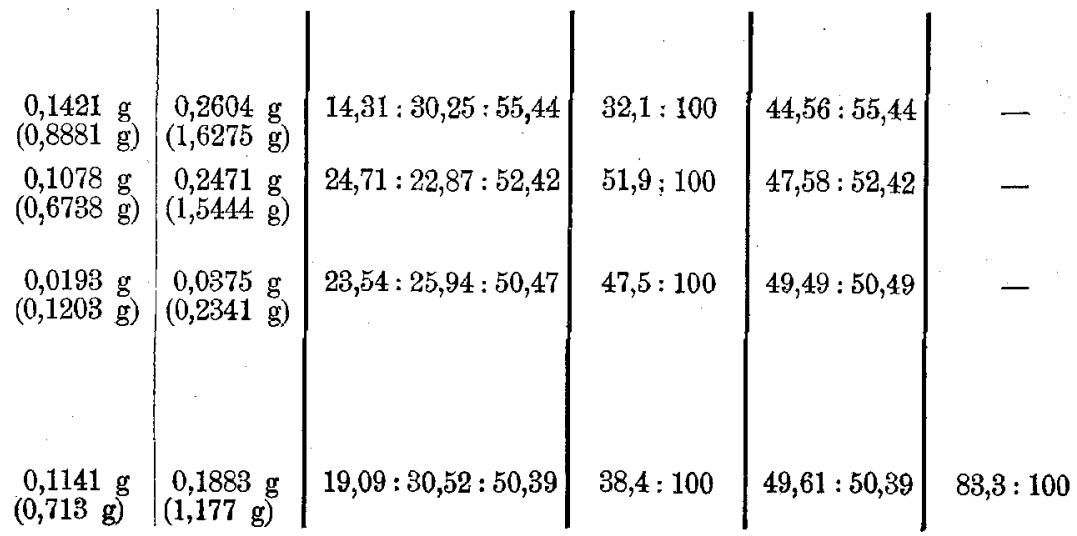


Tabelle V. Ascites bei Car-

\begin{tabular}{c}
\hline $\begin{array}{c}\text { Untersuchungs- } \\
\text { object. } \\
\text { Entnommen } \\
\text { am: }\end{array}$ \\
\hline \\
$\begin{array}{c}\text { Punctionsflüssig- } \\
\text { keit aus dem } \mathrm{Ab}- \\
\text { domen }\end{array}$
\end{tabular}

29. October 1901

id.

18. Decemb. 1901

id.

8. Januar 1902

id.

17. April 1902

id.

2. Mai 1902

id.

10. Juni 1902

id.

27. Juni 1902

id.

19. Juli 1902

id.

27. Juli 1902

id.

3. Septemb. 1902

rentar

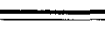

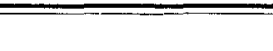


Ueb. d. Eiweissvertheilung in menschl. und thier. Körperflüssigkeiten. 573 cinom der Bauchorgane.

\begin{tabular}{|c|c|c|c|c|c|}
\hline $\begin{array}{c}\text { Stickstoff } \\
\text { der } \\
\text { Pseudo- } \\
\text { globulin- } \\
\text { fraction }\end{array}$ & $\begin{array}{c}\text { Stickstoff } \\
\text { der } \\
\text { A lbumin - } \\
\text { fraction }\end{array}$ & $\begin{array}{l}\text { Verhältniss der } \\
\text { drei Eiweiss- } \\
\text { fractionen } \\
\text { zu einander } \\
\text { in } \%\end{array}$ & $\begin{array}{l}\text { Verhältniss } \\
\text { der Euglo- } \\
\text { bulin- } \\
\text { fraction zum } \\
\text { Gesammt- } \\
\text { globulin }\end{array}$ & $\begin{array}{c}\text { Verhältniss } \\
\text { des } \\
\text { Globulins } \\
\text { zum } \\
\text { Albumin } \\
\text { in } \%\end{array}$ & $\begin{array}{l}\text { Verhältniss } \\
\text { des Stickstoffs } \\
\text { der coagula- } \\
\text { blen Eiweiss- } \\
\text { körper zum } \\
\text { Gesammt- } \\
\text { Stickstoff } \\
\text { in 0 }\end{array}$ \\
\hline berechnet & . & & & & \\
\hline $\begin{array}{c}0,04681 \mathrm{~g} \\
(0,2926 \mathrm{~g})\end{array}$ & $\left(\begin{array}{c}0,1111 \\
(0,6945\end{array}\right.$ & $12,37: 25,97: 61,65$ & $32,5: 100$ & $38,34: 61,65$ & - \\
\hline 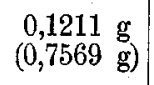 & $\left.\begin{array}{c}0,4288 \\
(2,6797 \\
\mathrm{g}\end{array}\right)$ & $10,99: 19,63: 69,45$ & $35,9: 100$ & $30,60: 69,40$ & - \\
\hline $\begin{array}{c}0,1452 \mathrm{~g} \\
(0,907 \mathrm{~g})\end{array}$ & $\begin{array}{c}0,3486 \mathrm{~g} \\
(2,178 \mathrm{~g})\end{array}$ & $11,75: 25,94: 62,25$ & $31,2: 100$ & $37,69: 62,25$ & - \\
\hline $\begin{array}{c}0,1064 \mathrm{~g} \\
(0,665 \mathrm{~g})\end{array}$ & $\left\{\begin{array}{c}0,4004 \mathrm{~g} \\
(2,502 \mathrm{~g})\end{array}\right.$ & $16,42: 17,54: 66,03$ & $48,3: 100$ & $33,96: 66,03$ & $94,7: 100$ \\
\hline $\begin{array}{c}0,1289 \\
(0,7744\end{array}$ & $\left(\begin{array}{c}0,3322 \mathrm{~g} \\
(3,2306 \mathrm{~g})\end{array}\right.$ & $11,76: 23,97: 64,27$ & $32,9: 100$ & $35,73: 64,27$ & $97: 100$ \\
\hline $\begin{array}{rr}0,1316 & \mathrm{~g} \\
(0,8225 & \mathrm{g})\end{array}$ & $\begin{array}{c}0,4445 \mathrm{~g} \\
(2,7781 \\
\mathrm{g})\end{array}$ & $20,6: 18,13: 61,26$ & $53,2: 100$ & $38,73: 61,26$ & $87,5: 100$ \\
\hline $\begin{array}{c}0,1659 \\
(1,0369 \\
\mathrm{g})\end{array}$ & $\left(\begin{array}{c}0,3654 \mathrm{~g} \\
(2,2837 \mathrm{~g})\end{array}\right.$ & $9,75: 28,18: 62,06$ & $25,7: 100$ & $37,93: 62,06$ & $90,5: 100$ \\
\hline $\begin{array}{cc}0,1631 & \mathrm{~g} \\
(1,0194 & \mathrm{g})\end{array}$ & $\begin{array}{l}0,4256 \mathrm{~g} \\
(2,66 \mathrm{~g})\end{array}$ & $12,21: 24,32: 63,47$ & $33,4: 100$ & $36,53: 63,47$ & $95,8: 100$ \\
\hline $\begin{array}{c}0,147 \mathrm{~g} \\
\left(0,9188^{\circ} \mathrm{g}\right)\end{array}$ & $\begin{array}{c}0,469 \mathrm{~g} \\
(2,931 \mathrm{~g})\end{array}$ & $9,78: 21,53: 68,69$ & $31,2: 100$ & $31,31: 68,69$ & $97,2: 100$ \\
\hline $\begin{array}{c}0,1416 \mathrm{~g} \\
(0,885 \mathrm{~g})\end{array}$ & $\left|\begin{array}{rr}0,4708 & \mathrm{~g} \\
(2,9425 & \mathrm{g})\end{array}\right|$ & $8,84: 21,07: 70,08$ & $29,5: 100$ & $29,91: 70,08$ & $97,2: 100$ \\
\hline
\end{tabular}


ersteren, $15,09 \%$, erreicht nicht einmal den niedrigsten, $16,53 \%$ der letzteren. Wenn wir aus den gefundenen Procentantheilen Mittelwerthe aufstellen, so gestaiten sie sich folgendermaassen:

\begin{tabular}{c|c|c|c|c|c}
\hline \hline Diagnose & $\begin{array}{c}\text { Euglo- } \\
\text { bulin } \\
\text { in \% }\end{array}$ & $\begin{array}{c}\text { Pseudo- } \\
\text { globulin } \\
\text { in \% }\end{array}$ & $\begin{array}{c}\text { Albumin } \\
\text { in \% }\end{array}$ & $\begin{array}{c}\text { Gesammt- } \\
\text { Globulin } \\
\text { in \% }\end{array}$ & $\begin{array}{c}\text { Albumin } \\
\text { in \% }\end{array}$ \\
\hline $\begin{array}{l}\text { Pleuritis exsudativa . . . } \\
\text { Hydrothorax bei cardialer }\end{array}$ & 21,23 & 25,27 & 53,5 & 46,5 & 53,5 \\
Staung . . . . . . & 13,13 & 28,09 & 58,78 & 41,22 & 58,78
\end{tabular}

Eine weitere Scheidung von Transsudat und Exsudat der Brusthöhle lässt sich zur Zeit n i ch t aufstellen, zumal Uebergänge zwischen beiden ausserordentlich häufig sind.

b) Punctionsfiüsвigkeiten der Peritonealhöhle.

(Siehe Tabelle III und IV S. 570 u. 571 und Tabelle V S. 572 u. 573.)

Die Gesammtglobulinwerthe bei Cirrbosis hepatis schwanken demnach zwischen $51,59 \%$ und $78,1 \%$, bei der cardialen Stauung zwischen $44,56 \%$ und $49,61 \%$, beim Carcinom zwischen $29,91 \%$ und $38,73 \%$, die entsprechenden Albuminwerthe zwischen $21,89 \%$ und $48,41 \%, 50,39 \%$ und $55,44 \%, 61,26 \%$ und $70,08 \%$ des Gesammteiweissgehaltes; es ist also klar ersichtlich, dass der Cirrhose die höchsten relativen Globulinwerthe, die niedrigsten Albuminwerthe, dem Careinom die niedrigsten Globulinwertbe, die höchsten Albuminwerthe zukommen. Zwischen der Cirrhose und dem Carcinom stehen die Werthe für den Ascites bei cardialer Stauung. Seine relativen Globulinwerthe erheben sich in keinem Falle so hoch wie die irgend eines Cirrbosefalles, seine Albuminwerthe erreichen bei Weitem nicht die des Careinoms.

Die Euglobulinwerthe der Cirrhose $(16,19 \%$ bis $45,26 \%)$ sind im Allgemeinen höber als bei cardialer Staung (14,31\% bis $24,71 \%$ ) und fast in jedem Falle höher als beim Carcinom $(8,84 \%$ bis $20,6 \%)$; die Pseudoglobulinwerthe sind in allen Fällen von Cirrhose $(31,09 \%$ bis $56,82 \%$ ) höher als bei der cardialen Staung $(22,87 \%$ bis $30,52 \%$ ) und viel höher als beim Carcinom $(18,13 \%$ bis $28,18 \%$ ). Die Werthe der Euglobulinfraction bei Cirrhose bilden 28,8\% bis $57,9 \%$, die der cardialen Stauung $32,1 \%$ bis $51,9 \%$, die des Carcinoms $25,7 \%$ bis $53,2 \%$ des Gesammtglobulingehaltes. 
Ueb. d. Eiweissvertheilung in menschl and thier. Körperflüssigkeiten. 575

Der Ascites bei Cirrhosis hepatis zeichnet sich also im Allgemeinen durch relativ hohe Pseudoglobulinwerthe (zwei Ausnahmsfälle unter 11 Fällen) und sehr niedrige Albuminwerthe (keine einzige Ausnahme!) aus; Ascites bei Carcinom zeigt in der Regel relativ niedrige Euglobulinwerthe (eine einzige Ausnahme unter 10 Fällen), die niedrigsten, die ich bei irgend einer mit Transsudation oder Exsudation verbundenen Erkrankung fand, und ausnahmslos sehr hohe Albuminwerthe, die höchsten, die ich bei meinen Untersuchungen ermittelt habe.

Als Mittelwerthe ergeben sich:

\begin{tabular}{c|c|c|c|c|c}
\hline Diagnose & $\begin{array}{c}\text { Euglo- } \\
\text { bulin } \\
\text { in \%\% }\end{array}$ & $\begin{array}{c}\text { Pseudo- } \\
\text { globulin } \\
\text { in \% }\end{array}$ & $\begin{array}{c}\text { Albumin } \\
\text { in \% }\end{array}$ & $\begin{array}{c}\text { Gesammt- } \\
\text { Globulin } \\
\text { in \% }\end{array}$ & $\begin{array}{c}\text { Albumin } \\
\text { in \% }\end{array}$ \\
\hline Ascites bei Cirrhosis hepatis & 25,56 & 37,29 & 37,15 & 62,85 & 37,15 \\
Ascites bei cardialer Stauung & 20,43 & 27,39 & 52,18 & 47,82 & 52,18 \\
Ascites bei Carcinom der & 12,44 & 22,63 & 64,92 & 35,07 & 64,92 \\
Bauchorgane ......
\end{tabular}

Ich habe die vorstehenden drei Krankheitsbilder absichtlich zusammengestellt, um darzuthun, dass immerhin gewisse Unterschiede in der Eiweissvertheilung der Ascitesflüssigkeiten zu finden sind, die wahrscheinlich Veränderungen des Stoffwechsels in bestimmter Richtung entsprechen dürften. Insbesondere möchte ich in dieser Beziehung auf die Ascitesflüssigkeiten bei Carcinom der Bauchorgane hinweisen, die, obwohl durch Carcinom der Leber, der Gallenblase, des Ovariums, des Magens und des Darmes bedingt, ausnahmslos die höchsten relativen Albuminwerthe, meistens die niedrigsten Euglobulinwerthe a ufwiesen. - Dass diese auffallende Uebereinstimmung auf eine gemeinsame Ursache zurückgeführt werden muss, ist wohl zweifellos. $\mathrm{Ob}$ dieselbe aber in der carcinomatösen Erkrankung an sich und die durch eine solche etwa erzeugte Stoffwechselveränderung oder in anderen Gründen zu suchen ist, kann bisher nicht festgestellt werden. - Sicher sind die auffallenden Befunde nicht der meist durch Carcinom bedingten Kachexiezuzuschreiben, da ich unter meinen Fällen mehrere hatte, die zur Zeit der Punction noch guten Ernährungszustand aufwiesen und einen, dessen subcutanes Fettgewebe ausserordentlich reichlich war. 


\begin{tabular}{|c|c|c|c|c|}
\hline 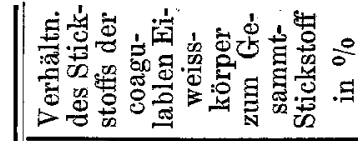 & 1 & \begin{tabular}{l}
8 \\
\hdashline \\
$\ddot{0}$ \\
$\infty$ \\
$\infty$
\end{tabular} & 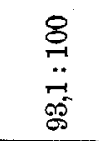 & 1 \\
\hline 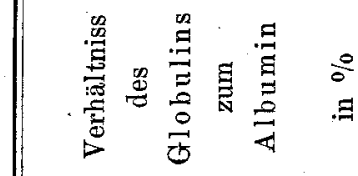 & 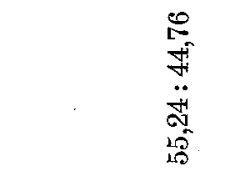 & 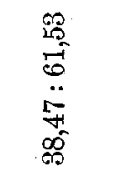 & 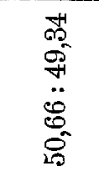 & 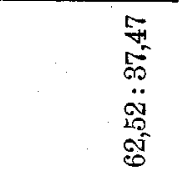 \\
\hline 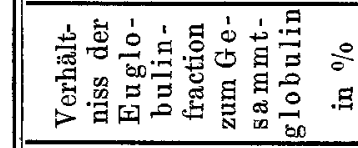 & 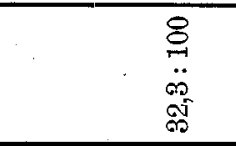 & 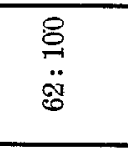 & $\begin{array}{l}\stackrel{8}{8} \\
\ddot{0} \\
: 0\end{array}$ & 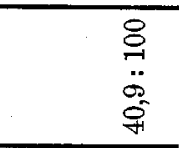 \\
\hline 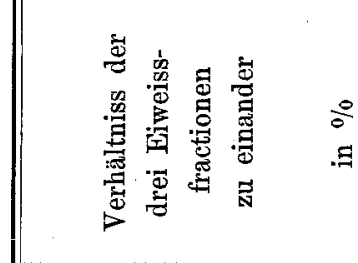 & 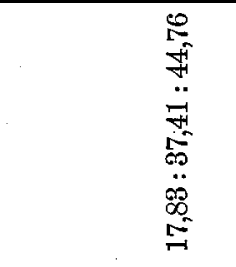 & 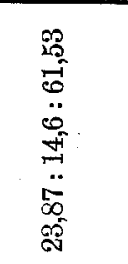 & 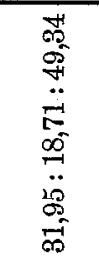 & 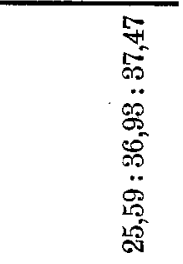 \\
\hline 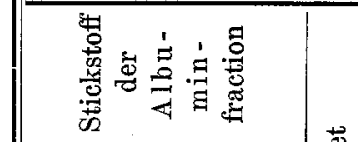 & 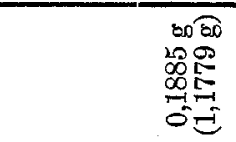 & 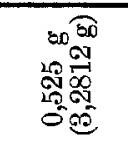 & 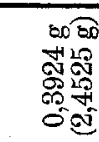 & 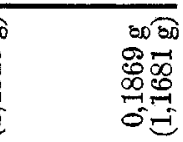 \\
\hline 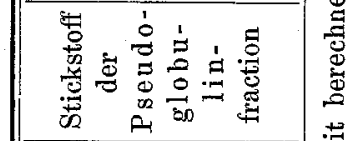 & 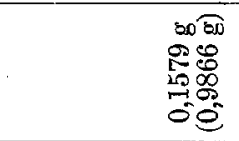 & 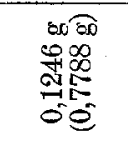 & 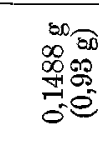 & 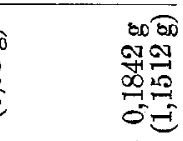 \\
\hline 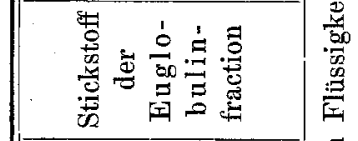 & 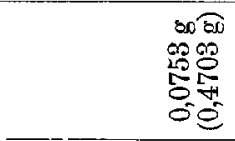 & 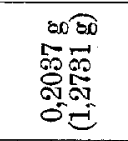 & 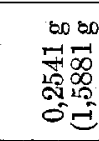 & 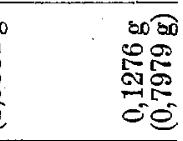 \\
\hline 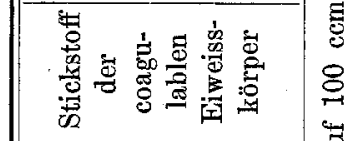 & 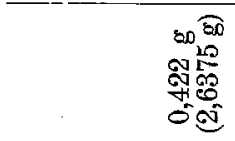 & 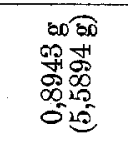 & $\begin{array}{l}50 \\
500 \\
50.0 \\
000 \\
0.0\end{array}$ & 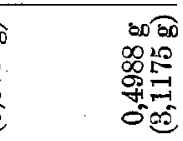 \\
\hline 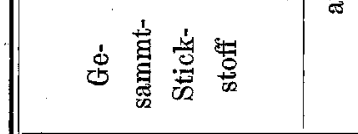 & $\begin{array}{l}50 \\
5 \\
5 \\
0 \\
0\end{array}$ & 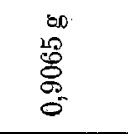 & 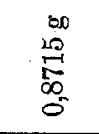 & $\begin{array}{l}20 \\
50 \\
\frac{10}{20} \\
0\end{array}$ \\
\hline 离 む & $\stackrel{\leftrightarrow}{g}$ & $\overrightarrow{\mathrm{g}}$ & ฐิ & 둥 \\
\hline 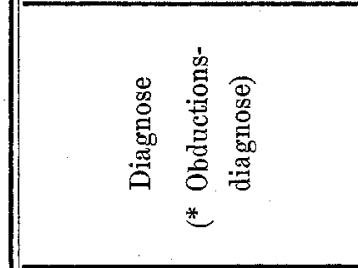 & 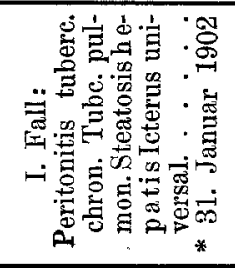 & 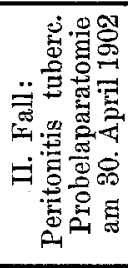 & 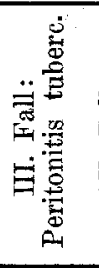 & 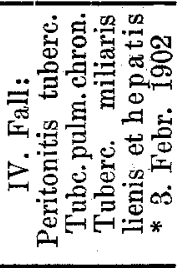 \\
\hline 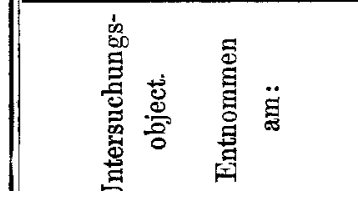 & 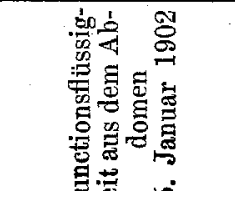 & 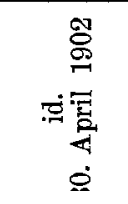 & 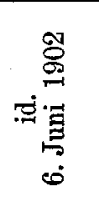 & 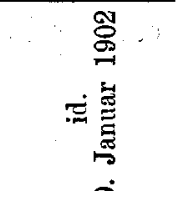 \\
\hline
\end{tabular}


Ueb. d. Eiweissvertheilung in menschl. und thier. Körperflüssigkeiten.

Desgleichen scheinen mir die bei Cirrhose gefundenen stets relativ niedrigen Albuminwerthe und meist hohen Pseudoglobulinwertbe der Beachtung werth, wenn ich auch, wie aus nachfolgender Untersuchungsreihe zu ersehen ist, unter vier Fällen von Peritonitis tuberculosa zwei fand, die bezüglich ihrer Eiweissvertheilung ein der Girrhose ähnliches Bild boten.

c) Ascites bei Peritonitis tuberculosa.

(Siehe Tabelle VI S. 576.)

Wir sehen hier in allen Eiweissgruppen ausserordentliche Schwankungen:

Gesammt-Globulin zwischen $38,47 \%$ bis $62,52 \%$, Albumin zwischen $37,47 \%$ und $61,53 \%$, Euglobulin zwischen $17,83 \%$ bis $31,95 \%$, Pseudoglobulin zwischen $14,6 \%$ bis $37,41 \%$ des Gesammteiweissgehaltes; der Antheil des Euglobulins am Gesammt-Globulin liegt zwischen $32,3 \%$ bis $63 \%$.

Es hiesse demnach den Zahlen Gewalt anthun, wollte ich auch hier Mittelwerthe aufstellen: es lässt sich eine Gesetzmässigkeit bezüglich der Eiweissvertheilung für die Peritonitis tuberculosa nicht erweisen. Es würde sogar unmöglich sein, Fall I und IV der Peritonitis tuberculosa mit ihren relativ hohen Pseudoglobulinwerthen und niedrigen Albuminwerthen von den Fällen von Cirrhosis hepatis, welche ganz ähnliche Eiweissvertheilung zeigen, aus einander zu halten, wenn wir nicht in dem viel höheren specifischen Gewicht und Gesammteiweissgehalt der Fälle von Peritonitis einen deutlichen Hinweis auf die entzundliche Art der Erkrankung fänden, Befunde, die - wie schọn früher bemerkt - für sich allein wohl nicht genügenden differential-diagnostischen Werth besitzen, als unterstützende Momente aber gewiss von Wichtigkeit sind.

Die Uebereinstimmung in den Werthen der Eiweissfractionen bei den zwei hervorgehobenen Fällen von Peritonitis mit jenen bei Cirrhosis hepatis mag durch die mannigfachsten Verhältnisse bedingt sein, sowie gerade die grossen quantitativen Schwankungen innerhalb der einzelnen Eiweisswerthe a lle r untersuchten Fälle von Peritonitis auf eine besondere Mannigfaltigkeit der durch diese Erkrankung bedingten localen Veränderungen innerhalb der Abdominalorgane hinweisen. Wir brauchen hier nur an Strangbildungen mit nacl-- 
folgenden Stauungen, an secundäre Degenerationen, an miliare Ausbreitung der Tuberculose auf die Organe der Peritonealhöhle selbst zu denken, Umstände, die wohl geeignet erscheinen, die anderen Krankheitsbildern zukommende Eiweissvertheilung vorzutäuschen. So finden wir z. B. bei jenen zwei Fällen von Peritonitis tuberculosa, deren procentuelle Eiweisswerthe jenen der Cirrhosis hepatis nahekommen, in den entsprechenden Obductionsdiagnosen, im Fall I "steatosis hepatis", im Fall IV "Tuberculosis miliaris hepatis" verzeichnet, und es erscheint die Annahme nicht grundlos, dass in diesen beiden Fällen gerade die Erkrankung der Leber die Eiweissvertheilung beeinflusst habe. Denn, dass diese letztere viel mehr vom pathologisch-anatomischen als vom klinischen Krankheitsbilde abhängt, ist von vorn herein klar; es kommt der Eiweissvertheilung in Transsudaten und Exsudaten eben immer nur die Bedeutung eines Krankheitss y mptoms zu, dessen Erforschung der diagnostischen Erkenntniss, die sich ja stets auf eine allseitige Erwägung und Zusammenstellung der einzelnen Symptome stützen muss, boffentlich noch werthvolle Dienste leisten wird. Wir dürfen auch nicht vergessen, dass es nicht immer einheitliche ätiologische Momente sind, welche die mit Transsudationen und Exsudationen einhergehenden Erkrankungen hervorrufen, so wie sich auch oft Uebergänge $z w i s c h e n$ reinem Transsudat und Exsudat finden lassen, z. B. Fntzündungen bei bereits bestehendem Transsudat, Stauungen mit nachfolgender Transsudation bei vorhandenem Exsudat, Umstände, die gewiss auf die Eiweissvertheilung rückwirken müssen.

So theilt Runeberg (36) die Ergüsse in seröse Höhlen ein:

1. in solche, die durch Affectionen in den serösen Membranen selbst, wie Fntzündungsprocesse, Tuberculose, Carcinom u. s. w., 2. durch venöse Stasis, sei es allgemeine oder locale, 3. durch hochgradige hydrämische Blutbeschaffenbeit (Amyloiddegeneration, Nephritis) entstehen, und schliesslich in solche, welche durch Combination von zwei oder aber von drei der früher genannten Ursachen bedingt werden.

In dieser Beziehung scheint mir ein erst ganz kürzlich erhobener Befund einer eigenen kurzen Besprechung werth. Es handelte sich um die Ascitesflüssigkeit eines stark ikterischen Patienten, der. in comatösem Zustand eingebracht wurde und schon nach zwei Tagen, 
Ueb. d. Eiweissvertheilung in menschl, und thier. Körperflüssigkeiten. $\quad 579$

kurz nach der Punction, starb. Die Obduction ergab ${ }^{\frac{1}{2}}$ ): Echinococcus der Leber, Thrombose der Vena portae, welche in den kleinen Aesten derselben begann und sich bis zur Vereinigung ihrer Wurzeln fortsetzte; ausserdem fand sich ein Spindelzellensarkom des rechtsseitigen pararenalen Bindegewebes mit gestielten Metastasen am Peritoneum. Ebenso auffallend wie der pathologischanatomische Befund ist der von mir erbobene chemische:

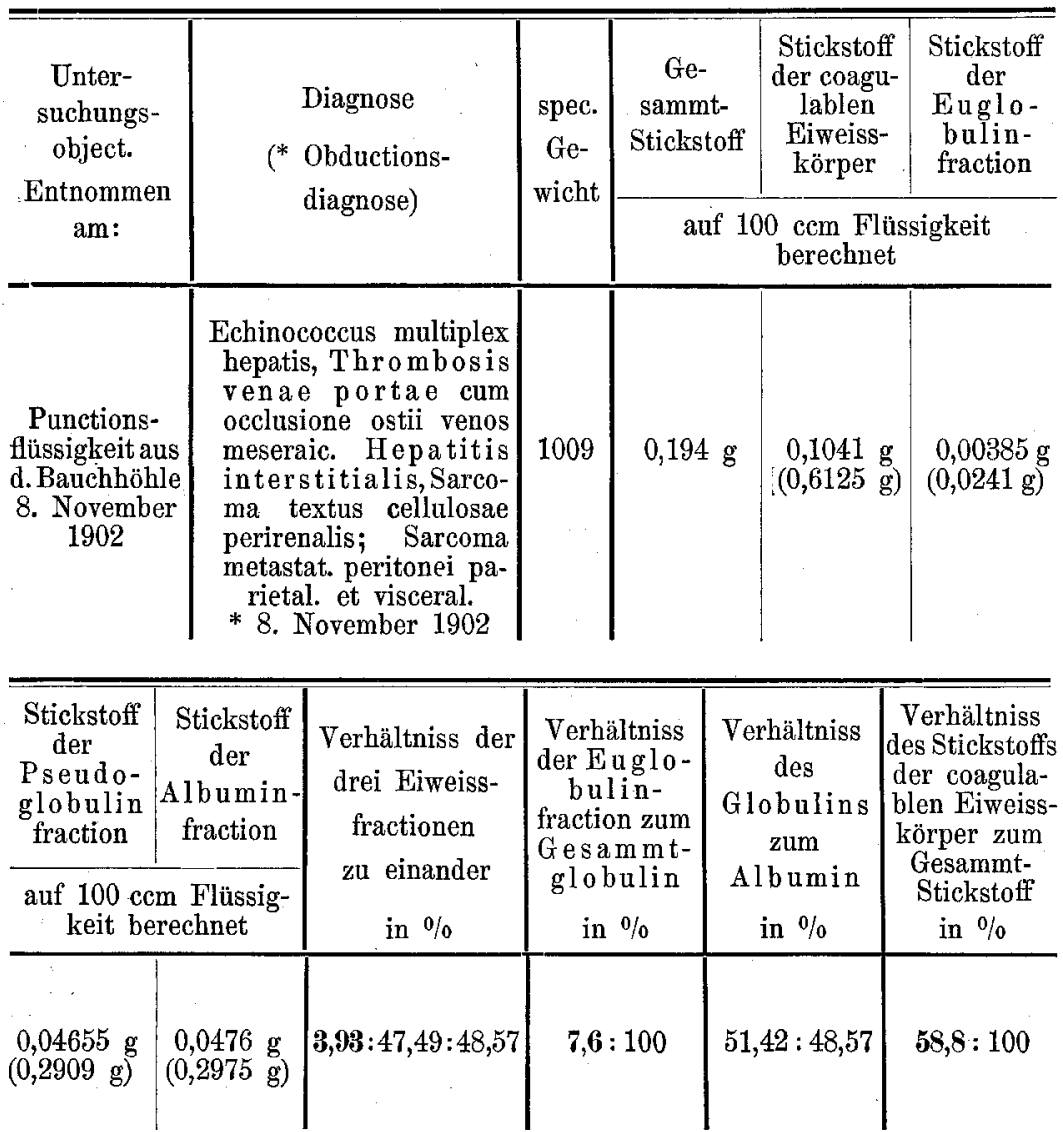

Während derselbe sich bezüglich des Ueberwiegens des Gesammtglobulins gegenüber dem Albumin sowie des relativ sehr hohen Pseudoglobulinwerthes den bei Cirrhosis hepatis und den zwei Fällen von Peritonitis tuberculosa mit Betheiligung der Leber gefundenen

1) An dieser Stelle erlaube ich mir, Herrn Prosectursadjuncten Dr. Karl Sternberg für die freundliche Ueberlassung der Obductionsdiagnosen bestens zu danken. 
Verhältnissen eng anschliesst, fand ich hier eine so niedrige relative Euglobulinmenge wie in keiner anderen der von mir untersuchten Punctionsflüssigkeiten. Da es immerhin möglich erscheint, dass die geringe Euglobulinausscheidung: mit der Pfortaderthrombose irgend einen Zusammenhang hat, glaubte ich, diesen Befund besonders hervorheben zu sollen. Leider stand mir kein Fall von durch Thrombosis venae portae allein bedingten Ascites zur Verfügung. Auf den soeben angeführten komme ich aus anderem Grunde noch einmal zurück.

Im Anschluss an meine Befunde möchte ich noch ein Verfahren berühren, welches gerade in letzter Zeit eine lebhafte Discussion hervorgerufen hat, ein Verfahren, das in äusserst expeditiver Weise die Unterscheidung zwischen Transsudat und Exsudat festzustellen sucht. Im Jahre 1886 hat F. Moritz $(37,38)$ angegeben, dass in mit Essigsäure schwach angesäuerten Exsudaten ein Eiweisskörper ausfällt, der im Ueberschuss der Essigsäure wieder in Lösung geht, während er in Transsudaten nicht oder nur spärlich zur Beobachtung gelangt. Er hat damals den Körper als globulinartig angesprochen. Paijkull, der von dieser Veröffentlichung offenbar keine Kenntniss hatte, fand mehrere Jahre später in "Transsudaten mit inflammatorischer Reizung" eine durch Essigsäure fällbare Substanz, die er als nicht in die Mucingruppe gehörig, sondern wegen ihres regelmässig erhobenen Phosphorgehaltes als Nucleoalbumin bezeichnete. Er fand diese Substanz bei Abwesenheit entzündlicher Reizung in den Transsudaten nicht vor. Runeberg empfiehlt 1897 Paijkull's Befund diagnostisch zu verwerthen, wie er es selbst seit Jahren auf seiner Klinik geübt batte, ein Verfahren, das auch anderen Orts, z. B. in unserem Laboratorium, zur rasehen Orientirung über die Natur der fraglichen Flüssigkeit in Gebrauch stand.

Umber (39) nahm vor Kurzem diese Frage wieder auf, isolirte den "durch schwache Essigsäure aus den ursprünglichen Exsudaten gefällten "Körper, fand ihn aber einerseits phosphorfrei, andererseits von den echten Mucinen durch seinen Stickstoffgehalt und seinen nur minimalen Gehalt an reducirender Substanz erheblich verschieden, gab ihm den Namen Serosamucin und hält es "für möglich, dass dieses eine pathognomonische Bedeutung erlangt zur Beurtheilung der Frage, ob ein Erguss exsudativer oder transsudativer Natur sei". Kurz nach ihm veröffentlichte 
Ueb. d. Eiweissvertheilung in menschl. und thier. Körperflüssigkeiten. 581

Staehelin (40) seine seit längerer Zeit über denselben Gegenstand angestellten Untersuchungen und sagt: "In allen entzündlichen Exsudaten konnte bei einer geringen Menge schwacher Essigsäure in der Kälte eine starke Trübung constatirt werden, bei den nicht entzündlichen blieb sie meist aus, doch erzeugte bisweilen a ch in sicheren Transsudaten, selbst in solchen, bei denen die Section die Abwesenheit von Entzündungsprocessen bestätigte, Essigsäure eine geringe Trübung. Da aber diese Trübung immer nur äusserst sehwach ausfiel, so wird hierdurch die Bedeutung dieser Reaction als eines werthvollen differential-diagnostischen Hülfsmittels nicht beeinträchtigt."

Staehelin's Essigsäurekörper löst sich schon in einem mässigen Ueberschuss von Essigsäure, fällt aus seinen Lösungen nicht durch Dialyse, wohl aber durch Halbsättigung mit Ammonsulfat aus, enthält keinen Phosphor, wesshalb Staehelin gleich Umber glaubt, dass Paijkull einen anderen Körper in der Hand gehabt habe, und dass sein bezw. Umber's Körper den Globulinen näher stehe als den Mucinen. Auch hält er Umber's Benennung "Serosamucin" für verfrüht und schlägt vor, den Körper vorläufig noch „den durch Essigsäure fällbaren Eiweisskörper der Exsudate" zu nennen. Staehelin versucht nun weiter festzustellen, ob derselbe identisch sei mit dem von verschiedenen Autoren im Harne bei gewissen Erkrankungen gefundenen durch Essigsäure fällbaren Eiweisskörper, den Reissner (41) als Mucin, Leube (42) als Paralbumin, Fr. Müller (43) als Globulin, Obermayer (44) als "Nucleoalbumin" bezeichnet hatten. Die damalige Bezeichnung "Nucleoalbumin" bezog sich auf eine Verbindung von Eiweiss und Nucleïn, welche nur durch starke Ansäuerung aus ihren Lösungen fällbar, unlöslich in Essigsäure war, durch Eintragen von Magnesiumsulfat bis zur Sättigung aus ihren Lösungen gefällt wurde, mit verdünten Säuren gekocht, keine reducirende Substanz, hingegen bei der Verdaung Nuclein abspaltete, daher phosphorhaltig war. Obermayer fand Nucleoalbumin in relativ grossen Mengen bei Icterus (ausnahmslos in allen 32 untersuchten Fällen, von welchen 28 ejweissfrei waren) und betrachtet das Auftreten des Nucleoalbumins als Ausdruck der parenchymatösen Degeneration der Niere; er findet es demnach in grösseren 
Mengen auch bei allen anderen Erkrankungen, bei welchen die erwähnte Nierenveränderung in besonders hohem Grade ausgebildet ist.

Mörner (45) bestritt die Nucleoalbuminnatur des Körpers und fasste ihn als chondroitinsehwefelsaures resp. taurocholsaures Eiweiss auf, was wiederum Staehelin nicht bestätigen kann, der schliesslich zu dem Schluss gelangt, dass „in Exsudaten und in gewissen Urinen ein durch Essigsäure fällbarer Eiweisskörper vorkommt, d e r den Globulinen nahestehen dürfte". Er hebt hervor, dass auch im Serum von Vesicatorenblasen durch verdünnte Essigsäure ein ziemlich starker Niederschlag entstehe, der sich im Ueberschuss sehr leicht wieder löst.

In allerjüngster Zeit beschreiben Rostoski (46) und Matsumoto einen Eiweisskörper, der aus dem Harn durch Essigsäure fällbar ist, keine reducirende Substanz und nur in einigen Fällen geringen Phosphorgehalt aufweist; dieser Körper gibt für Ammonsulfat nicht die niedrigen Ausfällungsgrenzen des Nucleoalbumins, sondern die des Euglobulins und Fibrinoglobulins, niemals die des Pseudoglobulins. Wenn ich nun die vorstehenden, einander grösstentheils widersprechenden Angaben mit jenen Befunden vergleiche, welche meine im Verein mit Freund seit langer Zeit angestellten Untersuchungen über die Globuline des Blutserums, der Transsudate und Exsudate ergaben, so drängt sich mir die Ueberzeugung auf, dass die verschiedenen Untersuchungsergebnisse der citirten Autoren auch thatsächlich verschiedenen - und zwar zwei verschiedenen - Körpern entsprechen. Dass Paijkull einerseits, Obermayer andererseits ein Nucleoalbumin in Händen hatten, kann kaum bezweifelt werden, und wenn die anderen Autoren in ihren durch Essigsäure gefällten Substanzen Phosphor nicht oder nicht immer nachweisen konnten, so ergibt sich daraus nur die Thatsache, dass sowohl in Transsudaten und Exsudaten als in eiweisshaltigen Harnen noch ein zweiter durch Essigsäure fällbarer, abernicht phosphorhaltiger Körper vorkomme. Der Erkenntniss der Natur desselben sind Staehelin und Rostoski am nächsten gekommen, indem der erstere ihn als eine dem Globulin nahestehende, der letztere als eine dem Euglobulin angehörige Substanz bezeichnet. Freund und ich haben festgestellt, dass durch ganz schwache Ansäuerung mit Essigsäure aus Blutserum, Trans- 
Ueb. d. Eiweissvertheilung in menschl. und thier. Körperflüssigkeiten.

sudaten und Exsudaten nur einganz bestimmter Globulinantheil und zwar der in salzfreiem Wasser un. lösliche Antheil der „Euglobuline“, das Para-Euglobulin, und zwar nur zum Theil (vom Para-Pseudoglobulin nur Spuren) gefällt werdeu kann. Dieser Körper geht bei stärkerer Ansäuerung wieder in Lösung, ist phosphorfrei und fällt erst bei langdauernder Dialyse gegen destillirtes Wasser aus seinen Lösungen wieder vollständig aus.

Von ihm streng geschieden ist das $\mathrm{Nucleoalbumin,} \mathrm{welches}$ nur bei starker Ansäuerung ausfällt, im Ueberschuss von Essigsäure nicht löslich und phosphorhaltig ist.

Der Körper, den Moritz, Umber, Staehelin und Rostoski beschrieben haben, scheint mir demnach nichts Anderes als d e r durch Essigsäure fällbare Antheil des Para-Euglobulin, der von Paijkull und Obermayer Nucleoalbumin gewesen zu $\operatorname{sein}^{1}$ ).

Für diese Annahme sprechen die übereinstimmenden Angaben von Moritz, Umber und Staehelin, dass ihre Substanzen durch schwache Ansäu erung gewonnen und im Ueberschuss von Essigsäure löslich seien, und dass sie keinen Phosphor nachweisen konnten. Freund und ich haben die Erfahrung gemacht, dass man bei der Fällung des Para-Euglobulins mittelst Essigsäure äusserst vorsichtig zu Werke gehen muss, dass es insbesondere bei behufs Reindarstellung: nöthigem Waschen mit essigsaurem Wasser dringend geboten ist, auf ganz schwach saure Reaction des Waschwassers zu achten, da bei der geringsten Ueberschreitung derselben der Körper wieder in Lösung geht.

Gegen unsere Annahme spräche der Befund Umber's, dass er in seinem fraglichen Körper reducirende Substanz nachweisen, der Staehelin's, dass er durch Dialyse den Körper aus seinen Lösungen

1) An dieser Stelle sei bemerkt, dass auch Pekelharing in seinen „Untersuchungen über das Fibrinferment", Amsterdam 1892, angibt, er habe aus dialysirtem Oxalatplasma durch Essigsäure sowohl „Paraglobulin“ als „Nucleoalbumin“ gewonnen; das erstere habe sich im Ueberschuss der Säure gelöst, letzteres nicht; er konnte sich nicht mit Sicherheit davon äberzeugen, dass das von ihm bereitete Nucleoalbumin ganz frei von Paraglobulin gewesen sei. Diese letztangeführte Angabe könnte vielleicht zur Deutung von Rostoski's unregelmässigen Phosphorbefunden herangezoger werden. 
nicht fällen konnte. Umber's Angabe erfährt aber dadurch eine bedeutende Einschränkung, dass er selbst nur einen minimalen Gehalt an reducirender Substanz (und zwar nur durch die BaboMeissner'sche Modification der Reductionsprobe) feststellen konnte, zumal Langstein $(47,48)$ aus allen von ihm untersuchten Eiweissstoffen Kohlehydrate gewinnen konnte.

Was aber Staehelin's Beobachtung betrifft, dürfte dieselbe sich aus der von uns gemachten erklären lassen, dass es nur durch langdauernde Dialyse gegen destillirtes Wasser gelingt, das durch Essigsäure gefällte Globulin aus seinen Lösungen wieder auszufällen.

Fassen wir demnach die von den genannten Autoren erhobenen Befunde mit unseren Erfahrungen zusammen, so gelangen wir zu folgenden Schlüssen :

1. Aus Transsudaten und Exsudaten (manchmal auch aus eiweisshaltigen Harnen) fällt bei schwacher Ansäuerung mittelst Essigsäure ein Eiweisskörper aus, der mit dem durch Essigsäure fällbaren Antheil des Para-Euglobulins identisch, in Exsudaten wahrscheinlich reichlicher zu finden ist als in Transsudaten.

2. Durch starke Ansäuerung lässt sich aus Exsudaten und gewissen Harnen (auch globulin- und albuminfreien) ein Eiweisskörper ausfällen, der höchstwahrscheinlich ein $\mathrm{Nucleoalbumin} \mathrm{(oder}$ Nucleoproteid) ist.

Die differential-diagnostische Bedeutung der Essigsäurereaction soll durch meine vorstehenden Darlegungen um so weniger geschmälert werden, als wir uns, wie bereits erwähnt, derselben in unserem Laboratorium schon seit Jahren zur raschen Orientirung für klinische Zwecke bedienen.

Schliesslich sei noch bemerkt, dass ich - wie aus den Tabellen ersichtlich - Umber's allerdings auf die Beobachtung von nur zwei Fällen sich stützende Angabe, dass bei wiederholter Ansammlung der Flüssigkeiten in den Leibeshöhlen die Albumincomponente procentisch viel schneller absinkt als die Globulincomponente, dass demnach der Procentsatz der Globuline in der Gesammtmenge progressiv ansteige, $\mathrm{nicht}$ bestätigt fand.

Desgleichen konnte ich mich von der von verschiedenen Autoren behaupteten Erhöhung des Gesammteiweissgehaltes nach wiederholter Punction nicht überzeugen. Diesbezüglich verweise ich nur auf meinen Fall I von Cirrhosis hepatis, welcher sechs Mal punktirt 
Ueb. d. Eiweissvertheilung in menschl. und thier. Ǩ̈rperflüssigkeiten. 585

wurde. Nach unwesentlicher Steigerung des Eiweissgehaltes (zweite Punction) sinkt derselbe stark ab (dritte Punction), um bis zur fünften Punction neuerlich anzusteigen, ohne aber die nach der ersten und zweiten Punction ermittelten Werthe zu erreichen; gerade die letzte, kurz vor dem Tode vorgenommene Punction förderte die eiweissärmste Flüssigkeit zu Tage.

Im Anhange seien noch die Untersuchung einer Anasarkaflüssigkeit, eines Hydrokelen- und eines Ovarialcysteninhaltes erwähnt: über den Gehalt an Gesammteiweiss in Oedemflüssigkeiten hat Hoffman $n$ eine grössere Arbeit veröffentlicht; auch Mya, Viglezio und Csatáry dehnten ibre Untersuchungen auf die Bestimmung des Globulins in Oedemflüssigkeiten aus; Mörner sowie Török und Voss (50) arbeiteten über den Eiweissgehalt von Hautblasen. Zahlreiche Analysen von Ovarialcysten - und Hydrokelenflüssigkeiten haben Hammarsten, Paijkull, Pfannenstiel (52) u. A. vorzugsweise im Hinblick auf die von Ersterem gefundenen Mucoidsubstanzen ausgeführt:

(Siehe Tabelle VII S. 586.)

Erwähnenswerth erscheint mir das totale Fehlen der Eu globulinfraction bei der Oedemflüssigkeit, der geringe Euglobulinwerth bei der Hydrokelenflüssigkeit, der ausserordentlich hohe des Ovarialcysteninhaltes. Doch möchte ich diesem letzteren Umstande um so weniger Bedeutung beilegen, als gerade in letzter Zeit im Ovarialcysteninhalt Eiweisskörper gefunden worden sind, die nicht zu den Globulinen gehören, mit ihnen aber wahrscheinlich bei der Fällung mittelst Ammonsulfat ausfallen (Leathes [53]).

\section{Blutsera.}

a) Menschenblutsera.

Die ersten verlässlichen Eiweissbestimmungen im Blutserum Gesunder und Kranker stammen von Becquerel und Rodier (54), die eine Verminderung des Gesammteiweissgebaltes bei Bright'schen Nierenerkrankungen, Krankheiten des Herzens mit Wassersucht und schweren puerperalen Processen fanden. C. Schmidt fand den Eiweissgehalt - der bei Gesunden nach Hammarsten (55) im Mittel 7,6199\% beträgt - bei einem Falle von schwerer Cholera stark erhöht, bei Nephritis verringert. Vereinzelte Analysen von Blutserum in verschiedenen Krankheiten stammen von $\mathrm{Hoppe-}$ Seyler (56) (bei melanetischem Sarkom und Chylurie), Manuel Leven (57) (Scorbut), Freund und Obermayer (58) (Lenkämie) 
Julius Joachim:

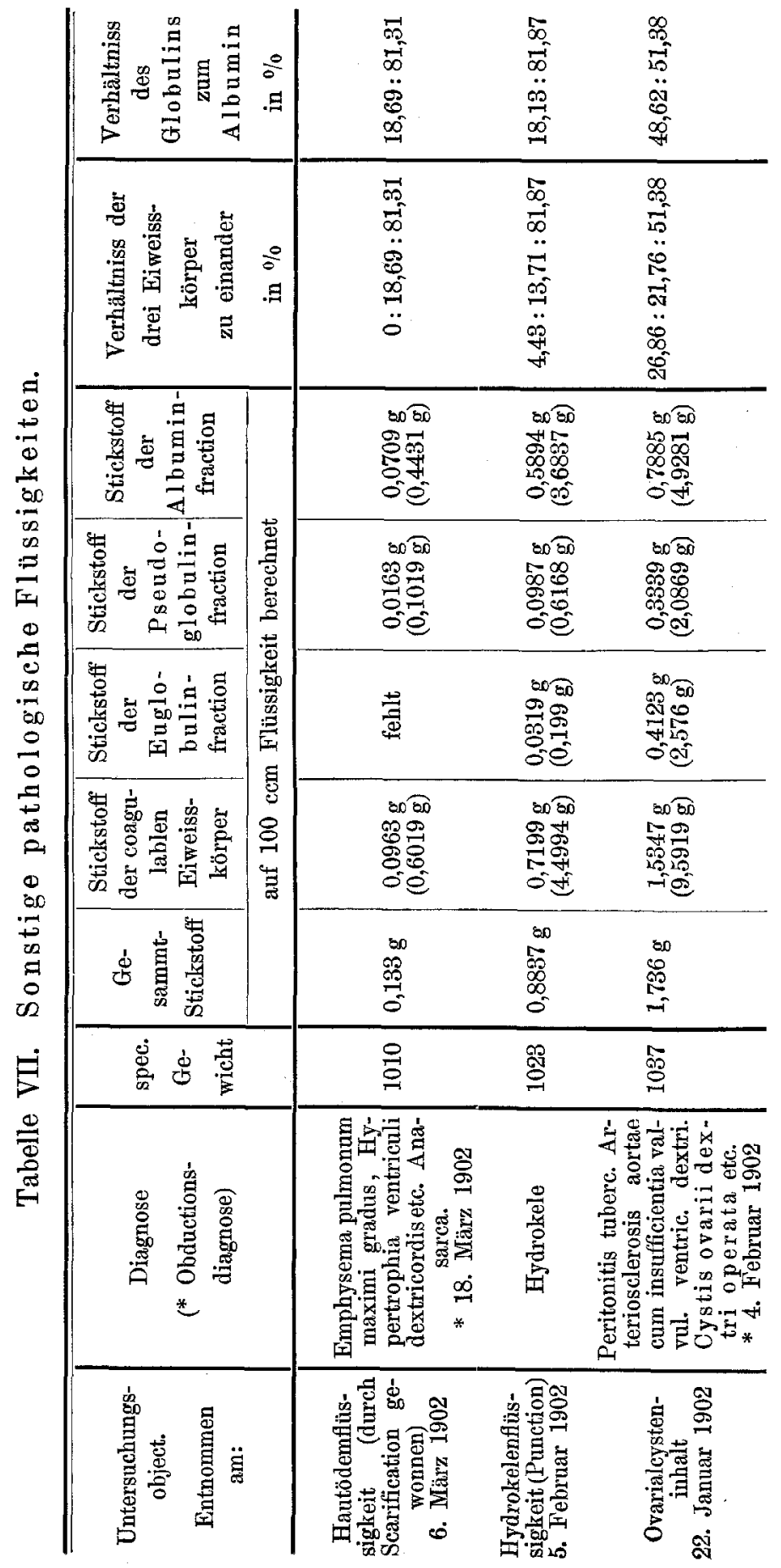


und Anderen, grössere Untersuchungsreihen von v. Jaksch (59) und v. Limbeck und F. Pick $(60,61)$. Ersterer rechnete den aus ca. 100 Blutseren durch das Kjeldahl-Verfahren bestimmten Stickstoff auf Eiweiss um und findet im Allgemeinen nur geringe Schwankungen des Eiweissgehaltes, der nur bei Herzaffectionen und bei mit Exsudationen einhergehenden Erkrankungen etwas steigt, bei Nierenerkrankungen, insbesondere aber bei Typhus und schweren Anämien, unter die Norm sinkt. Limbeck und Pick gelangen zu dem Schlusse, dass das Eiweiss des Blutserums im Vergleiche zu anderen Substanzen desselben ein in seiner Menge relativ fixer Körper ist, während die Haupteomponenten des Gesammteiweisses, das Albumin und Globulin, in ihrem Verhältniss zu einander in Krankheiten ausserordentlich schwanken. Hammarsten fand im Mittel für das normale Blut 4,52\% Albumin und $3,1 \%$ Globulin, Patein (62) $4,63 \%$ Albumin und 2,77\% Globulin, Estelle (63), der zwei Blutsera von Brightikern untersuchte, im ersten Falle 3,06\% Globulin und 5,44\% Albumin, im zweiten Falle 1,8\% Globulin und $3,6 \%$ Albumin; ähnliche Differenzen constatiren Csatáry bei Nieren-, H offmann bei verschiedenen Erkrankungen. Mya und Viglezio ziehen aus der Untersuchung von sieben Blutseren pathologischer Fälle den Schluss, dass das Verhältniss der Eiweisskörper im Blutserum zu einander während der Krankheiten hochgradig vorändert werde, insofern das Globulin $z u$, das Albumin a bnehme, eine Blutdrucksteigerung vor Alleın den Austritt von Albumin, weniger den des Globulins aus dem Blutserum vermehre.

Diesen Angaben gegenüber stehen die neueren Befunde von v. Limbeck und F. Pick (64), die bei einer grossen Anzahl von Krankheitsfällen das defibrinirte mit isotonischer Kochsalzlösung verdünnte und vom Sedimente abgeheberte Blut auf seine Eiweisszusammensetzung untersucht haben. Es ergaben sich für das Globulin in verschiedenen Erkrankungen procentische Schwankungen von $9,09 \%$ bis $74 \%$, für das Albumin solche von $26 \%$ bis $90,9 \%$ des Gesammteiweisses, und sie fühlen sich ausser Stande, ein für bestimmte Krankbeitsfälle charakteristisches Verhältniss der beiden Eiweisskörper des Blutes zu einander aufzustellen.

Von späteren Angaben seien noch die E. Freund's (65) erwähnt, welcher bei normalen und einigen pathologischen Fällen, insbesondere mit Stauungserscheinungen das Verhältniss des Globulins 


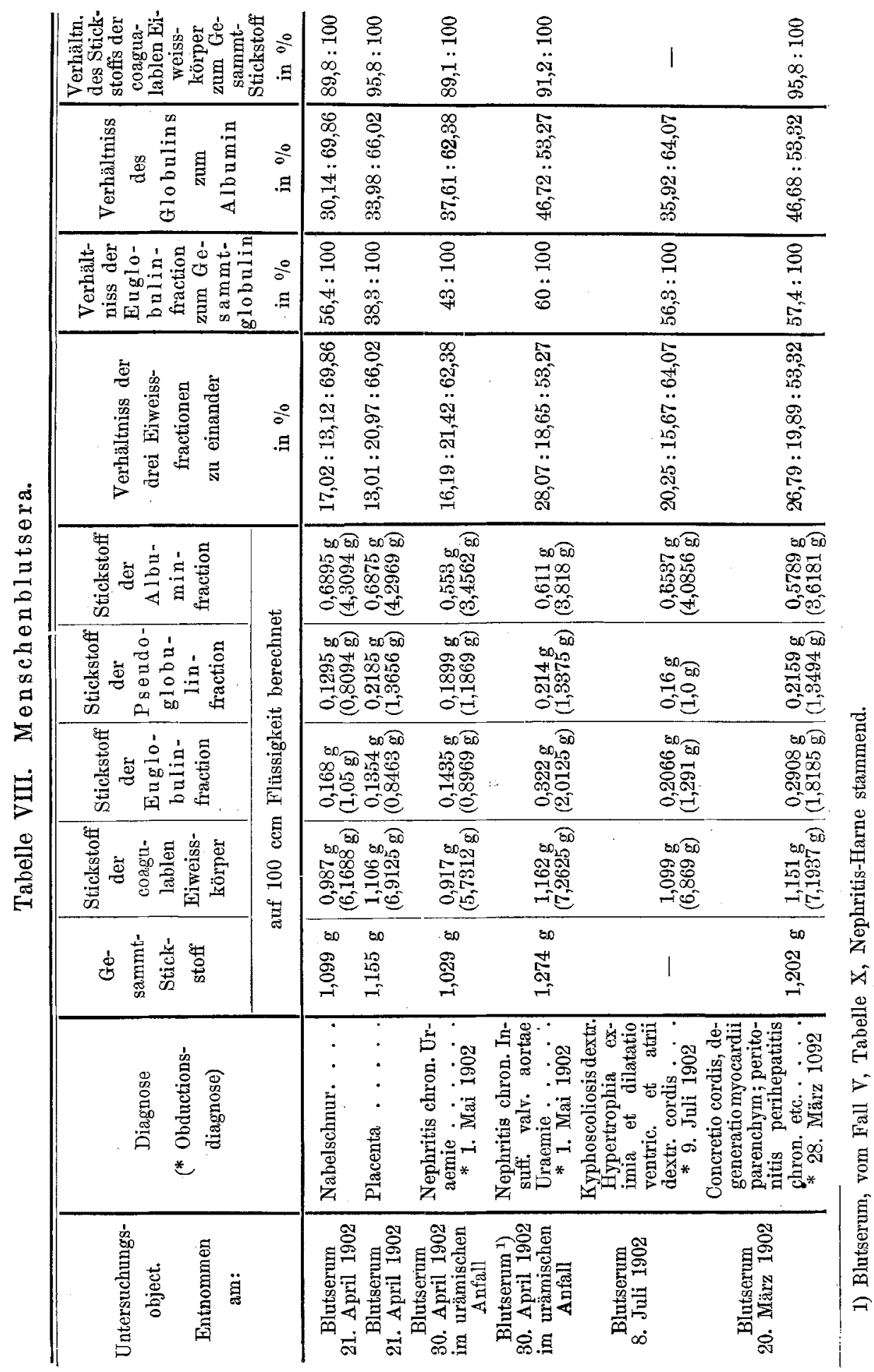


zum Albumin im Blute wie $1: 1,5$, hei Morbus Brightii in neun Fällen wie $1: 2-3$, bei einem Falle von peruiciöser Anämie ohne Albuminurie aber ebenfalls wie $1: 2$ fand.

Diesen zahlreichen Untersuchungen füge ich eine geringe Anzahl von Fällen an.

Des Interesses werth halte ich die Zahlen, die sich bei dem Placentarblutserum einerseits, bei dem Nabelschnurblutserum andererseits ergaben. Während das procentuelle Verhältniss zwischen Globulin und Albumin bei Beiden ungefähr das gleiche ist, zeigten sich in dem Verhältniss der Euglobulinfractionen zum Gesammtglobulin grosse Unterschiede, insofern es sich beim $\mathrm{N}$ abelschnurblutserum wie $56,4: 100$, beim Placentarblutserum wie $38,3: 100$ darstellte.

Nicht unerwähnt möge bleiben, dass auch Wallerstein ein Placentarblutserum untersucht hat und seine Zahlen beinahe genau mit den meinen übereinstimmen (Euglobulin : Gesammtglobulin = 38,76:100). (Tabelle VIII S. 588.)

\section{b) Thierblatsera.}

Das Verhältniss der Eiweisskörper im Blutserum von Thieren wurde von Hammarsten ${ }^{1}$ ) (Pferd, Rind, Kaninchen), Halliburton ${ }^{1}$ ) (Taube, Huhn, Schildkröte, Eidechse, Aal, Hai), M a y ${ }^{1}$ ) (Frosch), Wolfenden ${ }^{1}$ ) (Schlange) u. A. studirt; in neuester Zeit untersuchte Wallerstein die Blutsera vom Rind und Schaf auf ihren Euglobulingehalt, die vom Pferd, Schwein, Hund und Kaninchen auf ihre beiden Globuline.

Ich selbst habe die Blutsera von Hühnern, rom Rind und von Pferden verarbeitet. (Tabelle IX S. 590.)

Hier fällt vor Allem der Euglobulinwerth des Hühnerserums auf, der etwa das Doppelte von dem des Rinder- und des Pferdeserums beträgt; ferner zeichnet sich der Pseudoglobulinwerth des Pferdeserums durch seine Höhe aus.

Das Bestreben, die beobachteten grossen Schwankungen in der Eiweisszusammensetzung der Thiersera unter normalen und pathologischen Verhältnissen erklären, die Umstände ergründen zu können, welche diese Schwankungen bedingen, haben mehrere Forscher schon vor längerer Zeit veranlasst, dieser Frage experimentell näher zu treten.

1) Hammarsten, Halliburton, May und Wolfenden, citirt nach Halliburton, Lehrbuch der chemischen Physiologie und Pathologie. 1893. 
Burckhardt liess Hunde durch vier bis sechs Tage hungern und untersuchte deren Serum vor und $\mathrm{nach}$ dieser Zeit. Er constatirte Abnahme des Albumins unter gleichzeitiger relativer Steigerung des Globulins.

Tabelle IX. Thierblutsera.

\begin{tabular}{|c|c|c|c|c|c|c|c|}
\hline \multirow{2}{*}{$\begin{array}{c}\text { Unter- } \\
\text { suchungs- } \\
\text { object. } \\
\text { Entnommen } \\
\text { am: }\end{array}$} & \multirow[t]{2}{*}{ Thierart } & $\begin{array}{c}\text { Ge- } \\
\text { sammt- } \\
\text { Stickstoff }\end{array}$ & $\begin{array}{c}\text { Stickstoff } \\
\text { der coagu- } \\
\text { lablen } \\
\text { Eiweiss- } \\
\text { körper }\end{array}$ & $\begin{array}{c}\text { Stickstoff } \\
\text { der } \\
\text { Euglo- } \\
\text { bulin- } \\
\text { fraction }\end{array}$ & \multicolumn{2}{|c|}{$\begin{array}{c}\text { Stickstoff } \\
\text { der } \\
\text { Pseudo- } \\
\text { globu- } \\
\text { lin- } \\
\text { fractiour }\end{array}$} & $\begin{array}{l}\text { Stickstoff } \\
\text { der } \\
\text { Albu- } \\
\text { min- } \\
\text { fraction }\end{array}$ \\
\hline & & \multicolumn{6}{|c|}{ auf $100 \mathrm{ccm}$ Flüssigkeit berecbnet } \\
\hline Blutserum & Huhn. . . & $0,7875 \mathrm{~g}$ & $\begin{array}{c}0,714 \mathrm{~g} \\
(4,4605 \mathrm{~g})\end{array}$ & $0,2786 \mathrm{~g}$ & \multirow{2}{*}{\multicolumn{2}{|c|}{$\begin{array}{c}0,0945 \mathrm{~g} \\
(0,5906 \mathrm{~g}) \\
0,201 \mathrm{~g} \\
(1,2562 \mathrm{~g})\end{array}$}} & $0,2961 \mathrm{~g}$ \\
\hline Blutserum & & $1,237 \mathrm{~g}$ & $\begin{array}{c}1,141 \mathrm{~g} \\
(7,131 \mathrm{~g})\end{array}$ & $\begin{array}{c}0,318 \mathrm{~g} \\
(1,9875 \mathrm{~g})\end{array}$ & & & $\begin{array}{c}0,603 \mathrm{~g} \\
(3,7688 \mathrm{~g})\end{array}$ \\
\hline Blutserum & Pferd I . & $1,2215 \mathrm{~g}$ & $\begin{array}{c}1,1148 \mathrm{~g} \\
(6,9675 \mathrm{~g})\end{array}$ & $\left|\begin{array}{c}0,2009 \mathrm{~g} \\
(1,2556 \mathrm{~g})\end{array}\right|$ & \multicolumn{2}{|c|}{$\begin{array}{c}0,3276 \mathrm{~g} \\
(2,0475 \mathrm{~g})\end{array}$} & $\begin{array}{c}0,5362 \mathrm{~g} \\
(3,3513 \mathrm{~g})\end{array}$ \\
\hline Thierart & \multicolumn{2}{|c|}{$\begin{array}{l}\text { Verhältniss der } \\
\text { drei Eiweiss- } \\
\text { fractionen } \\
\text { zu einander } \\
\text { in } \%\end{array}$} & $\begin{array}{l}\text { Verhältniss } \\
\text { der Euglo- } \\
\text { bulin- } \\
\text { fraction zum } \\
\text { Gesammt- } \\
\text { globulin } \\
\quad \text { in } \%\end{array}$ & \multicolumn{2}{|c|}{$\begin{array}{l}\text { Verhältniss } \\
\text { des } \\
\text { Globulins } \\
\text { zum } \\
\text { Albumin } \\
\text { in } \%\end{array}$} & \begin{tabular}{|} 
Ver \\
des S \\
der \\
blen \\
körr \\
Ge \\
Sti \\
i
\end{tabular} & $\begin{array}{l}\text { rhältniss } \\
\text { Stickstoffs } \\
\text { coagula- } \\
\text { n Eiweiss- } \\
\text { rper zum } \\
\text { esammt- } \\
\text { tickstoff } \\
\text { in } \%\end{array}$ \\
\hline Huhn . . & \multicolumn{2}{|c|}{$41,63: 14,12: 44,25$} & $74,6: 100$ & \multicolumn{2}{|c|}{$55,75: 44,25$} & & $0,6: 100$ \\
\hline Rind . . & \multicolumn{2}{|c|}{$28,34: 17,91: 58,74$} & $68,4: 100$ & \multicolumn{2}{|c|}{$46,25: 53,74$} & & $2,2: 100$ \\
\hline Pferd I . . & \multicolumn{2}{|c|}{$18,87: 30,77: 50,36$} & $38: 100$ & \multicolumn{2}{|c|}{$49,64: 50,36$} & & $1,2: 190$ \\
\hline
\end{tabular}

Tiegel (60) fand bei Schlangen nach längerer Hungerperiode Abnahme des Gesammteiweisses bei relativer Zunahme des Globulins. Freilich fällte Burckhardt das Globulin mittelst Dialyse, Ti egel mittelst Kohlensäure, sie erhielten also nur bestimmte Globulinfractionsantheile, und Howells und Salvioli (67), die bereits die H a m marsten'sche Methode anwendeten, also wirklich in der Lage waren, das Gesammtglobulin zu bestimmen, wiesen die Befunde von Burckhardt und Tiegel als unrichtig zurück. Emmerich und Tsuboi (68) fanden, dass der Globulingehalt des Blutes von Kaninchen, die gegen Schweinerothlauf, und solcher, die gegen den Diplococeus pneumoniae immunisirt wurden, proportional der zunehmenden 
Immunität abnimmt (das Serum complet immunisirter Thiere erwies sich als nahezu globulinfrei), während die Menge des Serumalbumins eine bedeutende Vermehrung erfährt. Da aber die letztgenannten Autoren das Globulin mittelst Verdünnen des Serums mit dem zehnfachen Volum destillirten Wassers und Durchleiten von Kohlensäure gewannen, sind auch ihre Angaben nicht einwandfrei.

Ducceschi (69) studirte mit Hülfe von Hammarsten's Methode den Einfluss der Cachexia strumipriva auf die Zusammensetzung des Blutes von Hunden, fand vor Eintritt der Krämpfe eine procentuelle Steigerung des Albumins unter Abnahme des Globulins, während der Krampfzustände bis zum Ende fortschreitende Erhöhung des Globulins, Verminderung des Serumalbumins und der Totalmenge der Eiweissstoffe. Wallerstein liess zwei Kaninchen fünf Tage lang hungern und fand nach dieser Zeit eine Zunahme an Gesammtglobulin, weiche jedoch in einem Falle uberwiegend die Euglobulin-, im anderen Falle die Pseudoglobulinfraction betraf.

Ich selbst war in der Lage, Blutsera ${ }^{1}$ ) eines Pferdes vor und nach der Immunisirung mit Diphtherietoxin zu untersuchen. Es lag nahe, durch den Process der Immunisirung gewisse Veränderungen in der Zusammensetzung des Blutserums zu erwarten; ausserdem war in den letzten Jahren über das Verbältniss der Eiweisskörper zur Heilsubstanz nach Immunisirung mit Diphtherietoxin mehrfach gearbeitet worden. Seng (70) hatte festgestellt, dass das Antitoxin in dem "löslichen Globulin" gefunden werden konnte; Szontagh und Wellmann (71) haben angegeben, dass das Diphtherieserum einen höheren Eiweissgehalt als das normale zeige, und Atkinson (72) erklärt, dass die antitoxische Stärke des Serums stets vom Globulin bestimmt sei, ja, dass das Diphtherieantitoxin „eine Form des Globulins" darstelle. Schliesslich konnte E. P. Pick nachweisen, dass das Diphtherieantitoxin bei fractionirter Fällung mit Ammonsulfat mit der Pseudoglobulinfraction ausfalle.

Das Verhältniss der Eiweisskörper im Serum des zur Immunisirung bestimmten Thieres stellte sich folgendermaassen dar. (Tabelle a S. 592.)

Nach dreimonatlicher Immunisirung erlangte das Serum dieses Pferdes einen Werth von 500 Antitoxineinheiten, und zu dieser Zeit ist das Verhältniss der Eiweisskörper das folgende. (Tabelle b S. 592.)

1) Für die Ueberlassung derselben bin ich Herrn Assistenten Dr. O. Jellin ek zu besonderem Danke verpflichtet. 
a)

\begin{tabular}{|c|c|c|c|c|c|c|c|}
\hline \multirow[t]{2}{*}{$\begin{array}{l}\text { Unter- } \\
\text { suchungs- } \\
\text { object. } \\
\text { Entnommen } \\
\text { am: }\end{array}$} & \multirow[t]{2}{*}{ Thierart } & $\begin{array}{c}\text { Ge- } \\
\text { sammt- } \\
\text { Stickstoff }\end{array}$ & \begin{tabular}{|c|} 
Stickstoff \\
der coagu- \\
lablen \\
Eiweiss- \\
körper
\end{tabular} & $\begin{array}{l}\text { Stickstoff } \\
\text { der } \\
\text { Euglo- } \\
\text { bulin- } \\
\text { fraction }\end{array}$ & \multicolumn{2}{|c|}{$\begin{array}{c}\text { Stickstoff } \\
\text { der } \\
\text { Pseudo- } \\
\text { globu- } \\
\text { lin- } \\
\text { fraction }\end{array}$} & $\begin{array}{c}\text { Stickstoff } \\
\text { der } \\
\text { Albu- } \\
\text { min- } \\
\text { fraction }\end{array}$ \\
\hline & & \multicolumn{6}{|c|}{ auf $100 \mathrm{ccm}$ Flüssigkeit berechnet } \\
\hline $\begin{array}{l}\text { Blutserum } \\
\text { 28. Sept. } 1899 \\
\text { v or der Im- } \\
\text { munisirung }\end{array}$ & $\begin{array}{l}\text { Pferd II } \\
\text { Basilisk }\end{array}$ & $1,1795 \mathrm{~g}$ & $\begin{array}{c}1,0902 \mathrm{~g} \\
(6,8144 \mathrm{~g})\end{array}$ & $\begin{array}{c}0,1352 \mathrm{~g} \\
(0,845 \mathrm{~g})\end{array}$ & $\begin{array}{r}0,399 \\
(2,456\end{array}$ & $8 \mathrm{~g})$ & $\begin{array}{c}0,5328 \mathrm{~g} \\
(3,33 \mathrm{~g})\end{array}$ \\
\hline Thierart & $\begin{array}{r}\text { Verhältr } \\
\text { drei } \mathrm{E} \\
\text { kör } \\
\text { zu ein } \\
\text { in }\end{array}$ & $\begin{array}{l}\text { der } \\
\text { iss- } \\
\text { der }\end{array}$ & $\begin{array}{l}\text { Verhältniss } \\
\text { der Euglo- } \\
\text { bulin- } \\
\text { fraction zum } \\
\text { Gesammt- } \\
\text { globulin } \\
\text { in } \%\end{array}$ & $\begin{array}{r}\text { Verhäl } \\
\text { de } \\
\text { Globu } \\
\text { zu } \\
\text { Albu } \\
\text { in }\end{array}$ & $\begin{array}{l}\text { thiss } \\
\text { ilins } \\
\text { m } \\
\text { min } \\
\%\end{array}$ & $\begin{array}{c}\text { Ve } \\
\text { des } \\
\text { der } \\
\text { blen } \\
\text { körr } \\
\text { Ge } \\
\text { St }\end{array}$ & $\begin{array}{l}\text { erhältniss } \\
\text { Stickstoffs } \\
\text { r coagula- } \\
\text { en Eiweiss- } \\
\text { irper zum } \\
\text { yesammt- } \\
\text { Stickstoff } \\
\text { in } \%\end{array}$ \\
\hline $\begin{array}{l}\text { Pferd II } \\
\text { „Basilisk }\end{array}$ & $12,74: 37$ & $: 50,21$ & $25,6: 100$ & $49,78:$ & 50,21 & & $2,4: 100$ \\
\hline
\end{tabular}

b)

\begin{tabular}{|c|c|c|c|c|c|c|c|}
\hline \multirow[t]{2}{*}{$\begin{array}{l}\text { Unter- } \\
\text { suchungs- } \\
\text { object. } \\
\text { Entnommen } \\
\text { am: }\end{array}$} & \multirow[t]{2}{*}{ Thierart } & \multirow[t]{2}{*}{$\begin{array}{c}\text { Ge- } \\
\text { sammt- } \\
\text { Stickstoff }\end{array}$} & $\begin{array}{c}\text { Stickstoff } \\
\text { der coagu- } \\
\text { lablen } \\
\text { Eiweiss- } \\
\text { körper }\end{array}$ & $\begin{array}{l}\text { Stickstoff } \\
\text { der } \\
\text { Euglo- } \\
\text { bulin } \\
\text { fraction }\end{array}$ & \multicolumn{2}{|c|}{$\begin{array}{l}\text { Stickstoff } \\
\text { der } \\
\text { Pseudo- } \\
\text { globu- } \\
\text { lin- } \\
\text { fraction }\end{array}$} & \multirow{2}{*}{$\begin{array}{l}\text { Stickstoff } \\
\text { der } \\
\text { Albu- } \\
\text { min- } \\
\text { fraction }\end{array}$} \\
\hline & & & \multicolumn{4}{|c|}{ uf $100 \mathrm{ccm}$ Flüssigkeit berechnet } & \\
\hline $\begin{array}{c}\text { Blutserum } \\
25 . \text { Jan. } 1900 \\
\text { nach der Im- } \\
\text { munisirung }\end{array}$ & „Basilisk $^{\text {Pferd II }}$ & $1,3037 \mathrm{~g}$ & $\begin{array}{c}1,2443 \mathrm{~g} \\
(7,7769 \mathrm{~g})\end{array}$ & $\begin{array}{c}0,3056 \mathrm{~g} \\
(1,91 \mathrm{~g})\end{array}$ & \multicolumn{2}{|c|}{$\begin{array}{c}0,4284 \mathrm{~g} \\
(2,6775 \mathrm{~g})\end{array}$} & $\begin{array}{c}0,432 \mathrm{~g} \\
(2,7 \mathrm{~g})\end{array}$ \\
\hline Thierart & \multicolumn{2}{|c|}{$\begin{array}{l}\text { Verhältniss der } \\
\text { drei Eiweiss- } \\
\text { körper } \\
\text { zu einander } \\
\text { in } \%\end{array}$} & $\begin{array}{l}\text { Verhältniss } \\
\text { der Euglo- } \\
\text { bulin- } \\
\text { fraction zum } \\
\text { Gesammt- } \\
\text { globulin } \\
\text { in } \%\end{array}$ & \multicolumn{2}{|c|}{$\begin{array}{c}\text { Verhältniss } \\
\text { des } \\
\text { Globulins } \\
\text { zum } \\
\text { Album in } \\
\text { in } \%\end{array}$} & & $\begin{array}{l}\text { erhältniss } \\
\text { Stickstoffs } \\
\text { r coagula- } \\
\text { n Fiweiss- } \\
\text { irper zum } \\
\text { tesammt- } \\
\text { tickstoff } \\
\text { in } \%\end{array}$ \\
\hline "Bastilisk" & \multicolumn{2}{|c|}{$\mathbf{2 6 , 2 1}: 36,74: 37,05$} & $41,6: 100$ & \multicolumn{2}{|c|}{$62,95: 37,05$} & & $15,4: 100$ \\
\hline
\end{tabular}


Es hat sich demnach der Gesammteiweissgehalt nach der Immunisirung nur unwesentlich höher gezeigt. Hingegen ist eine sehr bedeutende Zunahme des Gesammtglobulins auf Kosten des Albumins eingetreten; doch betrifft diese nicht etwa das Pseudoglobulin, an welchem - wie oben erwähnt die wirksame Substanz haftet, s ondern das Euglobulin, welches keine Heilsubstanz enthält, indem dieses auf das Doppelte gestiegen, jenes nahezu gleich geblieben ist. Inwieweit hier individuelle Ver. schiedenheiten in der Zusammensetzung des Blutserums von Pferden mitspielen, ob die Vermehrung des Euglobulins mit der Immunisirung in directen Zusammenhang gebracht werden muss, dies zu entscheiden wäre Sache weiterer Untersuchungen. Die starke procentuelle Vermehrung des Gesammtglobulins, die Stejgerung des Euglobulins auf das Doppelte seines ursprünglichen Werthes lässt freilich einen directen Zusammenhang nicht unwahrscheinlich erscheinen. $\mathrm{Ob}$ der immerhin auffallende Umstand, dass gerade das Pseudogl obulin, der Träger des Antitoxins, durch die Immunisirung keine Veränderung erfahren hat, mit der von Pröscher (73) in jüngster Zeit publicirten Angabe, es sei ihm gelungen, e in eiweissfreies Diphtherieantitoxin zu gewinnen, zusammenhänge, muss gleichfalls dahingestellt bleiben.

Im Anschluss an die bisher vorgeführten Untersuchungen soll noch das in den Tabellen angeführte Verhältniss des Gesammtstickstoffs zu dem Stickstoff der coagulablen Eiweisskörper einer kurzen Betrachtung unterzogen werden:

In den meisten Fällen der besprochenen Bestimmungen wurde neben dem Gesammtstickstoff auch der Stickstoff der coagulablen Eiweisskörper gesondert bestimmt; überblickt man die entsprechenden Zahlen, so findet man, dass in allen daraufhin untersuchten Fällen der Gesammtstickstoff grösser als der Stickstoff der coagulablen Eiweisskörper ist. Die Differenz schwankt zwischen 83,3:100 und 98,6:100, wobei mit 100 der Gesammtstickstoff bezeichnet ist ${ }^{1}$ ). Eine Gesetzmässigkeit innerhalb der einzelnen Erkrankungen liess sich nicht feststellen, insbesondere möge darauf hingewiesen werden, dass auch bei carcinomatösen Er-

1) Dass diese grossen Schwankungen etwa auf Arbeitsfehler zurückzuführen waren, konnte ich dadurch ausschliessen, dass ich den direct bestimmten Stickstoff der coagulablen Eiweisskörper durch die Summe der aus den einzelnen Fractionen bestimmten Stickstoff werthen controlirte. 
krankungen die Zahlen bedeutenden Schwankungen unterliegen. Da wir über die Natur der Körper, welche durch den ni cht coagulablen Stickstoff repräsentirt werden, vorläufig nicht genügend orientirt sind, muss die Frage offen bleiben, ob in allen Fällen der nichtcoagulable Stickstoff auf dieselbe Ursache zurückzufübren ist; es ist selbstverständlich, dass es eine grosse Anzahl von Möglichkeiten gibt, durch welche das Vorhandensein beträchtlicher Mengen von nichtcoagulablen stickstoffhaltigen Körpern erklärt werden könnte. Ich erinnere hier nur an den Befund von Autolyse in carcinomatösem Gewebe von Petry (74), sowie an jenen Jacoby's (75) in der Leber bei Phosphorvergiftung. Inwiefern ein solcher Process bei pathologisch veränderten Organen sich schon in vi vo abspielt, muss allerdings noch dahingestellt bleiben.

Von Bedeutung zur Frklärung meiner Differenzen scheint auch die eben jetzt erschienene Arbeit von Embden und Knoop (76) zu sein, in der nunmehr mit voller Sicherheit das Vorhandensein von Albumosen im normalen Blute festgestellt wurde, womit der analoge Befund Hofmeister's (77) seine Bestätigung erfubr. In pathologischen Fällen wurden bereits wiederholt Albumosen im Blute constatirt (so E. Ludwig [78], Freund und Obermayer bei Leukämie, Freund [79] im Blute von an Sarkom Erkrankten), und es scheint die Annahme möglich, dass auch in meinen Fällen zum Mindesten ein Theil der Differenz zwischen Gesammtstickstoff und Stickstoff der coagulablen Eiweisskörper auf das Vorhandensein von Albumosen in den Blutseren sowohl als auch in Transsudaten und Exsudaten beruhe; in letzteren konnte U $\mathrm{mber}$ Albumosen regelmässig nachweisen. Ein anderer nicht zu vernachlässigender Theil des nichtcoagulablen Stickstoffs der Transsudate und Exsudate dürfte den von Hammarsten und Paijkull gefundenen Mucoildsubstanzen entsprechen.

Eine ganz exceptionelle Stellung nimmt der wegen seines geringen Euglobulinwerthes bereits hervorgehobene Fall von Pfortaderthrombose u. s. w. ein. Hier ergab sich, dass ca. $42 \%$ des gesammten Stickstoffs nichtcoagulablen Stoffen entsprach. Es liegt nahe, dieses Verhalten auf Beziehungen zurückzuführen, welche zwischen Leber einerseits und Darmschleimhaut andererseits bestehen; doch muss selbstverständlich offen gelassen werden, ob die hier constatirte Anhäufung stickstoffhaltiger nichtcoagulabler Producte in der durch die Thrombose der Pfortader 
Ueb. đ. Eiweissvertheilung in menschl. und thier. Körperflüssigkeiten. 595

gestörten Resorption oder einer Anomalie der Leberfunction begründet ist.

III. Untersuchungen von Nephritisharnen.

Der Erste, der im Harn Globulin nachwies, war J. C. L e hmann (80), der auch schon feststellen konnte, dass jeder eiweisshaltige Harn neben Albumin auch Globulin enthalte; zu dem gleichen Resultate gelangten nach ihm G. Edlefsen (81), Senator (82) und Bartels (83), während C. Gerhardt (84), Petri (85), Führy-Snethladge (86) und Heynsius (87) aus später zu erörternden Gründen nicht in allen ihren Fällen neben Albumin auch Globulin finden konnten. Im Gegensatz hiezu wollen Estelle und Maguire (88) in einem Falle nur Globulin gefunden haben. Den genannten Autoren standen allerdings nur die damaligen unvollkommenen Globulinfällungsmethoden (durch Dialyse, Essigsäure und Kohlensäure) zur Verfügung, wesshalb deren Resultate nicht mehr als einwandfrei bezeichnet werden können. Noch weniger verlässlich erscheinen uns die Angaben von Le co r ché und Talamon (89), Maguire oder die von Paton (90), welche wohl bereits im Besitze der Hammarsten'schen Methode der Globulinfällung, zur Bestimmung des Gesammteiweisses aber Methoden wählten, die nur approximative Schätzungen erlauben (Methode nach Roberts-Stolnik off, Essbach u. s. w.). Eine grössere Anzahl von eiweisshaltigen Harnen untersuchte F. A. Hoffmann (91) mit Hammarsten's Methode und gelangt zu dem Schlusse, dass der Eiweissquotient wobl keine differential-diagnostisch verwerthbaren Beziehungen zur Art der Nierenerkrankungen zeigt, jedoch insofern prognostische Bedeutung habe, als der Quotient während einer Besserung stetig wachse, d. h. je kleiner die relative Globulinmenge, desto besser sei die Prognose. Mit Hofmeister's Methode untersuchte nach $\mathrm{Pohl}$ noch Csatáry (92) in einer ausserordentlich gründlichen Arbeit etwa 250 Harne von 34 Kranken und kommt im Wesentlichen zu folgenden Schlussfolgerungen: Der Eiweissquotient hängt hauptsächlich von der Blutstromgeschwindigkeit in den Glomerulis ab; derselbe ist bei Fällen von Nephritis, bei denen der Stromgeschwindigkeit k e in Hinderniss entgegensteht, gross, im entgegengesetzten Falle klein. Die Hindernisse selbst können locale oder allgemeine sein. Locale Hindernisse sind z. B. amyloide Degeneration der Glomerulusgefässe, lurch Cylinder bedingte Stauung; allgemeine Hindernissc 
Tabelle X.

\begin{tabular}{|c|c|c|c|c|}
\hline $\begin{array}{c}\text { Unter- } \\
\text { suchungs- } \\
\text { object. } \\
\text { Entnommen }\end{array}$ & $\begin{array}{l}\text { Diagnose } \\
\text { (* Obductions- } \\
\text { diagnose) }\end{array}$ & $\begin{array}{c}24- \\
\text { stündige } \\
\text { Harn- } \\
\text { menge } \\
\text { spec. }\end{array}$ & Sedimentbefund & $\begin{array}{l}\text { Stickstoff } \\
\text { der coagu- } \\
\text { lablen } \\
\text { Eiweiss- } \\
\text { körper }\end{array}$ \\
\hline & & Reaction & & auf \\
\hline $\begin{array}{l}\text { Harn } \\
\text { 17. Februar } \\
1902\end{array}$ & $\begin{array}{c}\text { I. Fall: } \\
\text { Nephritis acuta }\end{array}$ & $\begin{array}{l}570 \mathrm{ccm} \\
1024 \\
\text { sauer }\end{array}$ & $\begin{array}{l}\text { Schleim, zahlreiche } \\
\text { Plattenepithelien, spär- } \\
\text { liche Leukocyten und } \\
\text { rothe Blutkörperchen, } \\
\text { ziemlich zahlreiche hya- } \\
\text { line, granulirte und } \\
\text { Epithelialcylinder }\end{array}$ & $\begin{array}{c}0,0577 \mathrm{~g} \\
(0,3609 \mathrm{~g})\end{array}$ \\
\hline $\begin{array}{l}\text { id. } \\
\text { 10. Februar } \\
1902\end{array}$ & $\begin{array}{c}\text { II. Fall: } \\
\text { Nephritis chronica }\end{array}$ & $\begin{array}{c}930 \mathrm{ccm} \\
1013 \\
\text { sauer }\end{array}$ & $\begin{array}{l}\text { Schleim, zahlreiche } \\
\text { Plattenepithelien, ver- } \\
\text { einzelte Leukocyten, } \\
\text { zahlreiche hyaline, gra- } \\
\text { nulirte und Epithelial- } \\
\text { cylinder }\end{array}$ & $\begin{array}{c}0,1304 \mathrm{~g} \\
(0,815 \mathrm{~g})\end{array}$ \\
\hline $\begin{array}{l}\text { id. } \\
\text { 14. März } \\
1902\end{array}$ & $\begin{array}{l}\text { III. Fall: } \\
\text { Nephritis chronica cum } \\
\text { atrophia renum granul. } \\
\text { Endocarditis, Pleuritis } \\
\text { Pneumonia lobul. etc. } \\
\text { * 3. April } 1902\end{array}$ & $\begin{array}{c}830 \mathrm{ccm} \\
1012 \\
\text { sauer }\end{array}$ & $\begin{array}{l}\text { Schleim, spärliche Leu- } \\
\text { kocyten und Harnsäure- } \\
\text { krystallen, zahlreiche } \\
\text { Plattenepithelien, zahl- } \\
\text { reiche hyaline, granu- } \\
\text { lirte, spärliche Epithe- } \\
\text { lialcylinder }\end{array}$ & $\begin{array}{c}0,0389 \mathrm{~g} \\
(0,2431 \mathrm{~g})\end{array}$ \\
\hline $\begin{array}{l}\text { id. } \\
\text { 9. Juli } \\
1902\end{array}$ & $\begin{array}{l}\text { IV. Fall: } \\
\text { Nephritis chronica cum } \\
\text { atrophia renum,Hyper- } \\
\text { trophia cordis } \\
\text { *2. August } 1902\end{array}$ & $\begin{array}{c}1175 \mathrm{ccm} \\
1015 \\
\text { sauer }\end{array}$ & $\begin{array}{l}\text { Schleim, spärliche Plat- } \\
\text { tenepithelien, zahl- } \\
\text { reicheLeukocyten, zahl- } \\
\text { reiche hyaline, granu- } \\
\text { lirte und Leukocyten- } \\
\text { cylinder }\end{array}$ & $\begin{array}{c}0,077 \mathrm{~g} \\
(0,4813 \mathrm{~g})\end{array}$ \\
\hline $\begin{array}{l}\text { id. } \\
\text { 30. April } \\
1902\end{array}$ & $\begin{array}{l}\text { V. Fall: } \\
\text { Nephritis chronica Ur- } \\
\text { aemie; Insufficientia } \\
\text { valv. aortae Pericar- } \\
\text { * 1. Mai } 1902\end{array}$ & $\begin{array}{c}1080 \mathrm{ccm} \\
1021 \\
\text { sauer }\end{array}$ & $\begin{array}{l}\text { Schleim, ziemlich zahl- } \\
\text { reiche Leukocyten, ein- } \\
\text { zelne rothe Blutkörper- } \\
\text { chen und verfettete } \\
\text { Nierenepithelien, zahl- } \\
\text { reiche hyaline, granu- } \\
\text { lirte und Epithelial- } \\
\text { cylinder }\end{array}$ & $\begin{array}{c}0,2318 \mathrm{~g} \\
(1,4487 \mathrm{~g})\end{array}$ \\
\hline $\begin{array}{l}\text { id. } \\
\text { 30. April } \\
1902\end{array}$ & $\begin{array}{l}\text { VI. Fall: } \\
\text { Nephr. subacuta recru- } \\
\text { descens; Haemorrha- } \\
\text { gia nuclei lentiformis } \\
\text { et thalami optici sin. } \\
\text { * 11. Mai } 1902\end{array}$ & $\begin{array}{c}870 \mathrm{ccm} \\
1014 \\
\text { sauer }\end{array}$ & $\begin{array}{l}\text { Schleim, spärl. Platten- } \\
\text { epithelien, Lenkocyten } \\
\text { u.rothe Blutkörperchen, } \\
\text { sehr zahlreiche hyaline } \\
\text { and granulirte Cylinder }\end{array}$ & $\begin{array}{c}0,112 \mathrm{~g} \\
(0,7 \mathrm{~g})\end{array}$ \\
\hline $\begin{array}{l}\text { id. } \\
\text { 1. September } \\
1902\end{array}$ & $\begin{array}{l}\text { VII. Fall: } \\
\text { Nephritis chron. A my- } \\
\text { loid o s is lienis hepa- } \\
\text { tis renumque Abscess. } \\
\text { musc. ileopsoatis para- } \\
\text { metrit. purul. dextr. } \\
\text { Endocardit. cum steno- } \\
\text { si ostii venos sin. etc. } \\
\text { * 16. Septemb. } 1902\end{array}$ & $\begin{array}{c}200 \mathrm{ccm} \\
1036 \\
\text { neutral }\end{array}$ & $\begin{array}{l}\text { Schleim, zahlr. Platten- } \\
\text { epithelien, spärliche } \\
\text { Leukocyten, massenhaft } \\
\text { hyaline, Erythrocyten-, } \\
\text { granulirte und wachs- } \\
\text { artige Cylinder }\end{array}$ & $\begin{array}{c}0,4288 \mathrm{~g} \\
(2,68 \mathrm{~g})\end{array}$ \\
\hline
\end{tabular}


Ueb. d. Eiweissvertheilung in menșchl. und thier. Körperflüssigkeiten. 597 Nephritis-Harne.

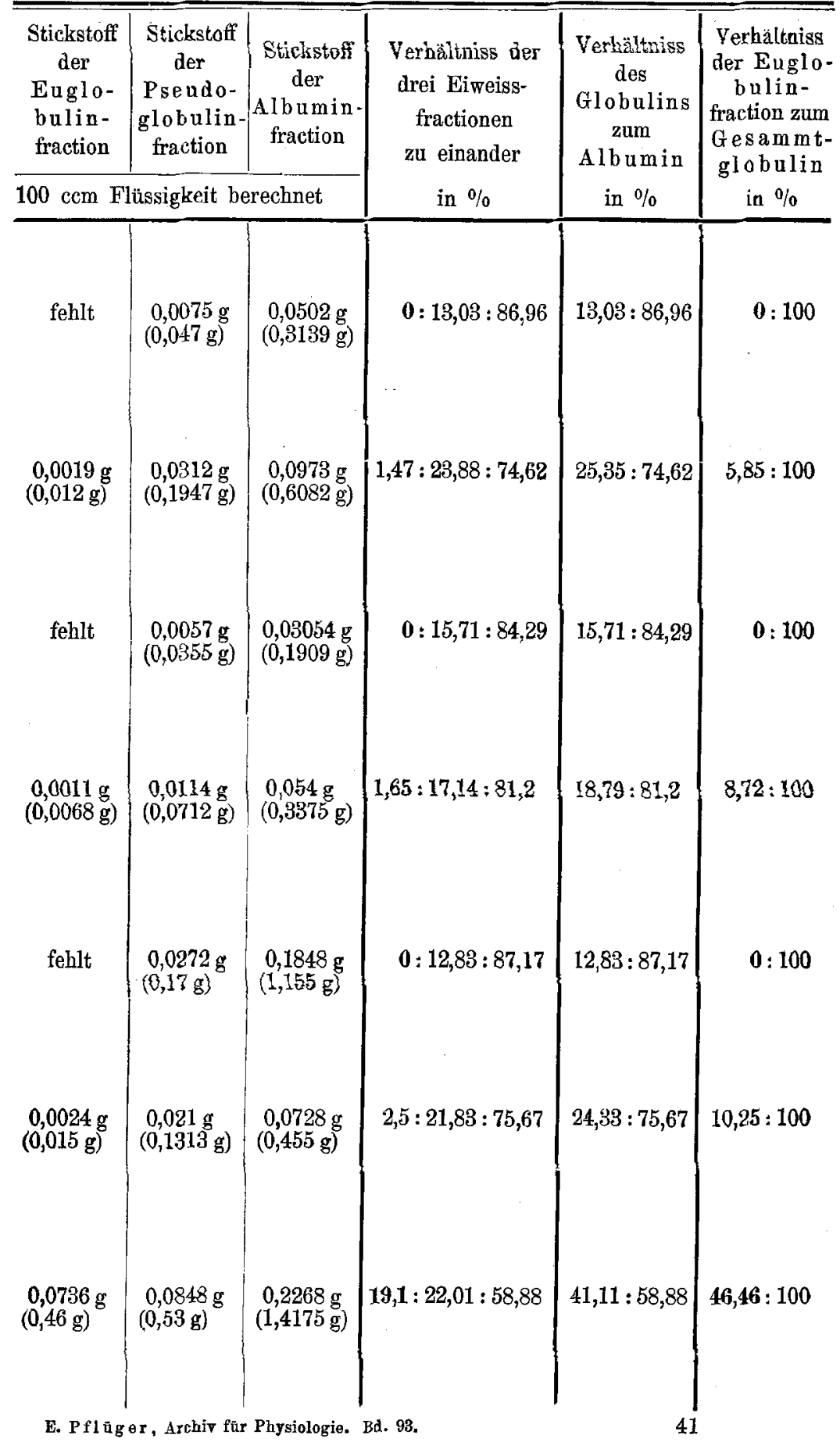


sind: Verfall der Kräfte, Herzmuskelschwäche, Oedeme. D e mentsprechend finden wir bei Amyloidniere den kleinsten Qu otienten (d.h. die relativ grösste Globulinmenge), bei genuiner Schrumpfniere den grössten. Das constante Ansteigen des Quotienten gibt eine günstige, das Sinken desselben eine ungünstige Prognose. Form und Intensität des Nierenprocesses erklären die Mengenverhältnisse von Albumin und Globulin nur insofern, als sie die Blutstromgeschwindigkeit in den Glomerulis beeinflussen.

Wie alle Autoren, die sich der neueren Globulinfällungsmethoden bedienen, findet auch Csatáry in allen Nephritisharnen neben Albumin auch Globulin.

Wenn ich von Daiber's (93) Arbeit absehe, der nach seinem eigenen Verfahren zahlreiche eiweisshaltige Harne untersucht hat, so liegen aus neuerer Zeit nur die Angaben Wallerstein's, die sich auf die Untersuchung zweier Harne von Nephritikern beschränken, und meine eigenen im Folgenden zusammengestellten Daten vor.

(Siehe Tabelle X S. 596 u. 597.)

Mein eben angeführtes Untersuchungsmaterial ist selbstverständlich zu klein, um daraus sichere diagnostisch oder prognostisch verwerthbare Schlüsse ziehen zu können. Trotzdem halte ich mich für berechtigt, auch bier gewisse in die Augen springende Befunde als nicht ganz bedeutungslos hervorzuheben, Befunde, zu denen ich nur durch die vorgeschrittenere Methodik gelangen konnte, die mir eine Zerlegung der Globuline gestattete.

Die Verhältnisszahlen zwischen Albumin und Globulin wechseln in meinen Fällen gleichwie in denen früherer Autoren sehr stark; der höchste von mir ermittelte Eiweissquotient beträgt 6,8 , der niedrigste 1,4 .

Schon Edlefsen und Senator hatten hervorgehoben, dass relativ am meisten Globulin bei der amyloiden Degeneration der Niere im Harne ausgeschieden werde, und in den Zahlen Csatáry's finden diese Befunde eine deutliche Bestätigung. Freilich fand Letzterer auch bei der hämorrhagischen Schrumpfni ere relativ hohe Globulinwerthe, doch glaube ich nicht fehlzugehen, wenn ich dies der Blutbeimischung zuschreibe.

Der von mir untersuchte Fall VII betrifft eine Patientin, die an einem langandauernden Eiterungsprocess (Psoasabscess und eitrige Parametritis) litt, in dessen Verlauf eine Nephritis mit a m y loider Degeneration der Niere, der Leber und der Milz hin- 
zutrat. Betrachtet man nun das Verhältniss zwischen Globulin und Albumin in diesem Falle im Vergleich zu allen übrigen von mir untersuchten, so ist es klar ersichtlich, dass auch hier die relativ höchste Globulinmenge dem Fall von amyloider Degeneration zukommt. Ein ähnliches Verhältniss findet übrigens auch Wallerstein in einem Falle von grosser weisser Niere mit Amyloiddegeneration der Glomeruli, dessen Eiweissquotient $(0,26)$ noch viel niedriger als der von Csatáry und $\mathrm{mir}$ gefundene ist.

Ueberblicken wir die Rubrik, welche die Verhältnisszahlen der drei Eiweissfractionen zu einander wiedergibt, so fällt sofort die gewiss interessante Thatsache in die Augen, dass, während ich Pseudoglobulin in jedem Nephritisharn finden konnte, Euglobulin in drei Fällenganz fehlte, in drei anderen nur in ganz geringen Mengen vorhanden war und nur im Fallevon Amyloiddegeneration dem Pseudoglobulin nahe kam: die grosse Globulinmenge im letzteren Falle ist also nicht durch Zunahme des auch bei anderen Nephritisfällen stets vorhandenen Pseudoglobulins, sondern lediglich durch ein bedeutendes Ansteigen der Euglobulinfraction bedingt. Während das Verhältniss des Euglobulins zum Gesammtglobulin in allen anderen Fällen zwischen 0-10:100 schwankt, beträgt dasselbe bei der Amyloiddegeneration 46:100, zweifellos ein auffallender Unterschied.

Die Angaben mehrerer älterer Autoren, die nicht in allen eiweisshaltigen Harnen neben Albumin auch Globulin nachweisen konnten, finden in meinen Befunden von Harnen, welche wohl Pseudoglobulin, aber kein Euglobulin enthielten, eine Erklärung, da sich mit jenen Methoden, die den erwähnten Autoren zu Gebote standen (Essigsäure, Kohlensäure, Verdünnen), wie Freund und ich nachgewiesen haben, nur ein bestimmter und geringer Theil der $\mathrm{Eu} \mathrm{g} \mathrm{l}_{\mathrm{ob}}$ u l in fraction (vom Pseudoglobulin nur Spuren) ausfällen lässt.

Wodurch das Fehlen oder nur spärliche Auftreten der Euglobulinfraction in den meisten Nephritisharnen einerseits, der hohe Euglobulingehalt desselben bei Amyloiddegeneration andererseits zu erklären sei, namentlich ob dies von einer verschiedenen Filtrationsfähigkeit und Diffusibilität der beiden Globuline bezw. von dem Zustand des Nierenfilters abhängig sei, lässt sich zur Zeit nicht sagen. Desgleichen muss die Frage offen bleiben, ob die gegenüber anderen Nephritisfällen auffallend hohe Euglobulinausscheidung bei Amyloid- 
degeneration nicht etwa weniger dureh die Art der Nierenerkrankungals durch die Amyloiddegeneration der übrigen Organe (Milz, Leber u. s. w.) bedingt sei.

Es ergeben sich aus meinen Untersuchungen somit folgendeThatsachen:

1. Von den bisher im Blutserum nachgewiesenen Eiweisskörpern lassen sich in Harnen von Nephritikern regelmässig nachweisen Albumin und Pseudoglobulin; die Albuminmenge übertrifft zumeist die Globulinmenge.

2. Euglobulin konnte selbst in eiweissreichen Harnen entweder überbaupt nicht oder nur in sehr geringen Mengen nachgewiesen werden.

3. Bei Amyloiddegeneration ist die Gesammtglobulinausscheidung gegenüber der des Albumins ausserordentlich gesteigert; diese Steigerung betrifft nicht die Pseudoglobulin-, sondern nur die Euglobulinfraction.

\section{Literatarverzeichniss.}

1) O. Hammarsten, Ueber das Paraglobulin. Pflüger's Archiv Bd. 17.

2) J. Pohl, Ein neues Verfahren zur Bestimmung des Globulins im Harn und in serösen Flüssigkeiten. Archir für experimentelle Pathalogie und Pharmakologie Bd. 20 S. 426.

3) G. Ka u d e r, Zur Kenntniss der Eiweisskörper des Blutserums. Daselbst S. 411.

4) A. E. Burckhardt, Beiträge zur Chemie und Physiologie des Blutserums. Daselbst Bd. 16 S. 322.

5) 0. Hammarsten, Ueber die Anwendbarkeit des Magnesiumsulfates zur Trennung und quantitativen Bestimmung von Serumalbumin und Globulin. Zeitschrift für physiologische Chemie Bd. 8 s. 467.

6) E. Marcus, Ueber in Wasser lösliches Serumglobulin. Daselbst Bd. 28 S. 559.

7) Fuld und K. Spiro, Ueber labende und labhemmende Wirkung des Blutes. Zeitschrift f. physiol. Chemie Bd. 31 S. 132.

8) E. P. Pick, Zur Kenntniss der Immunkörper. Beiträge zur chemischen Physiologie und Pathologie Bd. 1 Heft 7 bis 12.

9) E. Freund und J. Joachim, Zur Kenntniss der Serumglobuline. Daselbst Bd. 36 s. 407.

10) J. König und W. Kisch, Zur Untersuchung der Handelspeptone. Zeitschrift für analytische Chemie Bd. 28 S. 193. 
Ueb. d. Eiweissvertheilung in menschl. und thier. Körperflüssigkeiten.

11) S. Wallerstein, Quantitative Bestimmung der Globuline im Blutserum und in anderen thierischen Flüssigkeiten. Inaug.-Dissert. Strassburg 1902.

12) N. Pato n, Ueber das Verhältniss der Eiweisskörper im Harn bei A lbuminurie. Brit. med. journ. 1890, 26. Juni, referirt im Centralblatt f. klin. Medicin Bd. 12 S. 523.

13) C. Schmidt, Charakteristik der epidemischen Cholera gegenüber verwandten Transsudationsprocessen. Leipzig 1850. G. Reyher.

14) Hoppe, Analyse von Peritonealexsudaten bei Cirrhose. Deutsche Klinik 1853 S. 405.

15) Derselbe, Ueber seröse Transsudate. Virchow's Archiv Bd. 9 S. 245.

16) Wachsmuth, Ueber die Menge der festen Bestandtheile und des Eiweisses in verschiedenen Exsudaten des menschlichen Körpers. Virchow's Archiv Bd. 7 S. 330.

17) Mehu, Études sur les liquides epanchements dans la pleure. Arch. génér. de Médic. Juin et Juillet 1872.

18) W. Reuss, Beiträge zur klin. Beurtheilung von Exsudaten u. Transsudaten. Deutsches Archiv für klinische Medicin Bd. 24 S. 581.

19) Derselbe, Das Verhältniss des specifischen Gewichtes zum Eiweissgehalt in serösen Flüssigkeiten. Daselbst Bd. 28 S. 317.

20) J. W. Runeberg, Klinische Studien über Transsudationsprocesse. Daselbst Bd. 34 S. 1.

21) Bernheim, Beiträge zur Chemie der Exsudate u. Transsudate. Virchow's Arehiv Bd. 81 S. 274.

22) Sansoni und Fornaca, Experimenteller Beitrag zur chem. Kenntniss der Körperhöhlenflüssigkeiten durch die Stickstoffbestimmung. Riforma med. 1894 Nr. 163.

23) Neuenkirchen, Ueber die Verwerthbarkeit des specifischen Gewichts und des Eiweissgehaltes pathologischer Trans- und Exsudate u. s. w. Inaug.-Dissert. Dorpat 1888.

24) Lunin, Zur Diagnostik der pathol. Trans- und Exsudate mit Hülfe des specif: Gewichtes. Dorpat 1892.

25) Citron, Zur klin. Würdigung des Eiweissgehaltes und des specif. Gewichtes pathologischer Flüssigkeiten. Deutsches Arch. f. klin. Med. Bd. 46 S. 129.

26) F. A. Ho ffm a nn, Ueber den Eiweissgehalt der A scitesflüssigkeiten. Virch o w's Aich. Bd. 78 S. 250.

27) Derselbe, Der Eiweissgehalt der Oedemflüssigkeiten. Deutsches Arch. f. klin Med. Bd. 44 S. 313.

28) Derselbe, Globulinbestimmungen in Ascitesflüssigkeiten. Arch. f. exper. Path. u. Pharm. Bd. 16.

29) v. Jaksch, Ueber den Eiweissgehalt krankhafter Ergüsse. Zeitschrift für klin. Med. Bd. 23 S. 225.

30) Ad. Ott, Ueber den Eiweissgehalt pathol. Flüssigkeiten. Zeitschrift für Heilkunde Bd. 17 S. 283.

31) Fichtner, Globulinbestimmungen in Ascitesflüssigkeiten. Deutsches Archiv f. klin. Med. Bd. 44 S. 323. 
32) G. Mya ed A. Viglezio, Ricerche quantitative sulle sostanze albuminose del siero dei trasudati ed essudati, Rivista clinica. Archivio ital. di clin. med. vol. 27. 1888.

83) A. Csatáry, Ueber Globulinurie II. Deutsch. Arch. f. klin. Med. Bd, 48 S. 358.

34) L. Paijkull, Beiträge zur Kenntniss von der Chemie der serösen Exsudate, Referat Hammarsten's in Maly's Jahresbericht über die Fortschritte der Thierchemie Bd. 22 S. 558.

35) 0. Hammarsten, Ueber das Vorkommen von Mucoïdsubstanzen in Ascitesflüssigkeiten, Autoreferat in Maly's Jahresbericht Bd. $20 \mathrm{~S} .419$.

36) J. W. Runeberg, Von der diagnostischen Bedeutung des Fiweissgehaltes in pathologischen Trans- und Exsudaten. Berliner klin. Wochenschrift S. 710. 1897.

37) F. Moritz, Beitrag zur Lehre von den Exsudaten und Transsudaten. Inaug.Dissert. München 1886; auch veröffentlicht in den „Arbeiten aus dem med. klin. Institut Mänchen" Bd. 1.

38) Derselbe, Ueber den durch Essigsäure fällbaren Eiweisskörpor in Exsudaten. Münch. med. Wochenschrift Nr. 42. 1902.

39) F. Umber, Ueber autolytische Vorgänge in Exsudaten. Daselbst Nr. 28. 1902.

40) R. Staehelin, Ueber den durch Essigsäure fällbaren Eiweisskörper der Transsudate und des Urins. Daselbst Nr. 34. 1902.

41) Reissner, Virchow's Arch. Bd. 24 S. 191.

42) Leube, Sitzungsbericht der phys.-med. Societät zu Erlangen. Lieferung 10 Jahrg. 1878.

49) Fr. Müll e r, Mittheilungen aus der med. Klinik zu Würzburg Bd. 1 S. 259. 1885.

44) F. Obermayer, Ueber Nucleoalbuminausscheidung im Harn. Centralblatt für klin. Med. Bd. 13 S. 1. 1892.

45) K. A. H. Mörner, Skandinav. Arch. f. Physiologie Bd. 6 S. 332.1895.

46) Rostoski, Ueber das sogenannte Nucleoalbumin des Harns, Referat in der: Münch, med. Wochenschr. Nr. 40 S. 1685. 1902.

47) L. Langstein, Ueber die gerinnbaren Stoffe des Eierklars. Beiträge zur chem. Physiol. u. Pathol. Bd. 1 S. 83.

48) Derselbe, Die Kohlehydrate der Eiweisskörper des Blutserums. Münch. med. Wochenschr. Nr. 45. 1902.

49) K. A. H. Mörner, Untersuchung der Blasenflüssigkeit nach Verbrennung der Haut. Skandinav. Arch. f. Physiol. Bd. 5 S. 272.

50) L. Török und B. Voss, Der Eiweissgehalt des Serums von Hautblasen. Magyar. Orv. Arch. Bd. 1 S. 76.

51) O. Hammarsten, Ueber Metalbumin und Paralbumin. Upsala Läkaref. förh. 16.

52) J. Pfannenstiel, Ueber die Pseudomucine der cystischen Ovarialgeschwülste. Arch. f. Gynäkol. Bd. 38 3. Heft S. 86.

53) J. B. Leathes, Beiträge zur Chemie der Ovarialmucoïde. Arch. f, exper. Path. u. Pharm. Bd. 43 S. 245.

54) Becquerel und Rodier, Untersuchungen über die Zusammensetzung des Blutes im gesunden und kranken Zustand. Erlangen 1845.

55) Hammarsten, Pflüger's Archiv Bd. 18. 
56) Hoppe-Seyler, Zeitschrift f. phys. Chemie Bd. 15. S. 179, und Maly's Jahrbücher Bd. 1. S. 113 (Referat).

57) Manuel Leven, Gazette médicale de Paris S. 493. 1871.

58) E. Freund u. F. Obermaye r, Ueber die chemische Zusammensetzung des leukämischen Blutes. Zeitschrift f. phys. Chemie Bd. 15 S. 310.

59) v. Jaksch, Ueber die Zusammensetzung des Blutes gesunder und kranker. Menschen. Zeitschrift f. klin. Med. Bd. 23 S. 187.

60) v. Limbeck und F. Pick, Ueber die quantitativen Verhältnisse der Eiweisskörper im Blutserum von Kranken, I. Mittheilung. Prager med. Wochenschrift $1893 \mathrm{Nr}$. 12-14.

61) Dieselben, II. Mittheilung. Deutsche med. Wochenschr. 1894 Nr. 27.

62) Patein, Gehaltsbestimmungen der Eiweissstoffe im Blutserum. Journ. Pharm. Chim. Bd. 10 S. 249.1899.

63) Estelle, Revue mensuelle S. 704. 1880.

64) v: Limbeck, Grundriss einer klinischen Pathologie des Blutes 2. Aufl. 1896.

65) E. Freund, Ueber chemische und physikalische Verhältnisse des Blutes bei Morbus Brightii. Wiener klin. Rundschau. 1895.

66) Tiegel, Pflüger's Archiv Bd. 23 S. 278.

67) Howells and Salvioli, Journ. of Physiol. tom. 7 S. 322.

68) R. Emmerich und Jiro Tsuboi, Die Natur der Schutz- und Heilsubstanz des Blutes. Verhandlungen des 11. Congresses f. innere Medicin zu Leipzig, Bergmann, S. 202. Wiesbaden 1892.

69) V. Ducceschi, Ueber die Bluteiweissstoffe des Hundes im Verhältniss mit den Folgen der Schilddrüsenexstirpation. Centralblatt f. Physiologie Bd. 9 S. 360 und Arch. ital. biol. Bd. 24.

70) W. Seng, Ueber die qualitativen und quantitativen Verhältnisse der Eiweisskörper im Diphtherieheilserum. Zeitschr. f. Hygiene u. Infectionskrankheiten Bd. 31 s. 513.

71) F. Szontagh u. O. Wellmann, Vergleichende Untersuchungen von normalem und Diphtherieserum. Maggar. Orv. Arch. S. 337. 1898.

72) J. P. Atkinson, The fraktional precipitation of the globulin and albumin of normal horses serum and diphtheria-antitoxic-serum etc. Journ. of exp. med. Bd. 5 S. 67.

73) Proescher, Ueber eiweissfreies Diphtherieantitoxin. Münch. med. WochenNr. 28 S. 1176. 1902.

74) E. Petry, Ein Beitrag zur Chemie maligner Geschwülste. Zeitschrift f. phys. Chemie Bd. 27 S. 398.

75) M. Jakoby, Ueber die Beziehungen der Leber- und Blutveränderungen bei Phosphorvergiftung zur Autolyse. Daselbst Bd. 30 S. 174.

76) G. Embden und F. Knoop, Ueber das Verhalten der Albumosen in der Darmwand und über das Vorkommen von Albumosen im Blute. Beiträge zur chem. Phys. u. Path. Bd. 3 S. 120.

77) F. Hofmeister, Zur Lehre vom Pepton, IV. über die Verbreitung des Peptons im Thierkörper. Zeitschrift f. phys. Chemie Bd. 6 S. 51.

78) E. Ludwig, Anzeiger der Gesellschaft der Aerzte $1882 \mathrm{Nr} .13$.

79) E. Freund, Zur Diagnose des Carcinoms. Wiener med. Blätter 1885 Nr. 9. 
80) J. C. Lehmann, Virchow's Archiv Bd. 36 S. 125.

81) G. Edlefs en, Deutsch. Arch. f. klin. Med. Bd. 7 S. 67.

82) Senator, Virchow's Archiv Bd. 60 S. 476.

83) Bartels, Ziemssen's Handbuch Bd. 9 S. 465.

84) C. Gerhardt, Deutsch. Arch. f. klin. Med. Bd. 5 S. 212.

85) Petri, Dissertation. Berlin 1876.

86) Führy-Snethlage, Deutsch. Arch. f. klin. Med. Bd. 17 S. 418.

87) Heynsius, Deutsch. Arch. f. klin. Med. Bd. 22 S. 435.

88) Maguire, The Albumens of the Urin. Lancet Bd. 1 S. 1062 u. 1106.1886.

89) Lecorché et Talamon, Traité de l'albuminurie. 1888.

$90)$ D. N. Paton, The systematic examination of the urine for proteids etc. Edinb. med. journ. 1888. (Referat im Centralblatt f. klin. Med. Bd. 10 s. 417.)

91) F. A. Hoffmann, Ueber das Verhältniss zwischen Serumalbumin und Globulin in eiweissführenden Harnen. Virchow's Archiv Bd. 89 S. 271.

92) A. Csatáry, Ueber Globulinurie I. Deutsch. Arch. f. klin. Med. Bd. 47 S. 159.

93) A. Daiber, Ueber die Bestimmung von Globulin neben Albumin im Harn. Correspondenzblatt für Schweizer Aerzte Bd. 25 S. 394. 